\title{
Food and Nutrition in India: Facts and Interpretations
}

ANGUS DEATON, JEAN DRÈZE

This paper reviews recent evidence on food intake and nutrition in India. It attempts to make sense of various puzzles, particularly the decline of average calorie intake during the last 25 years. This decline has occurred across the distribution of real per capita expenditure, in spite of increases in real income and no long-term increase in the relative price of food. One hypothesis is that calorie requirements have declined due to lower levels of physical activity or improvements in the health environment. If correct, this does not imply that there are no calorie deficits in the Indian population - nothing could be further from the truth. These deficits are reflected in some of the worst anthropometric indicators in the world, and the sluggish rate of improvement of these indicators is of major concern. Yet recent trends remain confused and there is an urgent need for better nutrition monitoring.

We are grateful to Reetika Khera, Anima Rani and Thu Vu for help in the preparation of this paper, and to G N V Brahmam for detailed clarifications relating to National Nutrition Monitoring Bureau data. We would also like to thank Linda Adair, Harold Alderman, David Atkin, Joachim von Braun, Anne Case, Noel Cameron, Bruno Dorin, Himanshu, S Mahendra Dev, J V Meenakshi, K V Radha Krishna, Abhijit Sen, Rekha Sharma, Priyanka Sinha, Veena Shatrugna, Alessandro Tarozzi and especially A Vaidyanathan for helpful discussions. The authors are solely responsible for the views expressed herein.

Angus Deaton (deaton@princeton.edu) is with Princeton University and Jean Dreze (jaandaraz@gmail.com) is with the G B Pant Social Science Institute, Allahabad.

\section{Introduction}

7 he Indian economy has recently grown at historically unprecedented rates and is now one of the fastest-growing economies in the world. Real GDP per head grew at 3.95\% a year from 1980 to 2005 , and at $5.4 \%$ a year from 2000 to 2005 . Measured at international prices, real per capita income in India, which was two-thirds of Kenya's in 1950, and about the same as Nigeria's, is now two and a half times as large as per capita income in both countries. Real per capita consumption has also grown rapidly, at $2.2 \%$ a year in the 1980 s, at $2.5 \%$ a year in the 1990 s, and at $3.9 \%$ a year from 2000 to 2005 . Although the household survey data show much slower rates of per capita consumption growth than do these national accounts estimates, even these slower growth rates are associated with a substantial decrease in poverty since the early 1980s (Deaton and Drèze 2002 and Himanshu 2007). Yet, per capita calorie intake is declining, as is the intake of many other nutrients; indeed fats are the only major nutrient group whose per capita consumption is unambiguously increasing. Today, more than three quarters of the population live in households with per capita calorie consumption below 2,100 per day in urban areas and 2,400 per day in rural areas - numbers that are often cited as "minimum requirements" in India.

A related concern is that anthropometric indicators of nutrition in India, for both adults and children, are among the worst in the world. Furthermore, the improvement of these measures of nutrition appears to be slow relative to what might be expected in the light of international experience and of India's recent high rates of economic growth. Indeed, according to the National Family Health Survey, the proportion of underweight children remained virtually unchanged between 1998-99 and 2005-06 (from $47 \%$ to $46 \%$ for the age group of o-3 years). Undernutrition levels in India remain higher than for most countries of subSaharan Africa, even though those countries are currently much poorer than India, have grown much more slowly, and have much higher levels of infant and child mortality.

In this paper, we do not attempt to provide a complete and fully documented story of poverty, nutrition and growth in India. In fact, we doubt that such an account is currently possible. Instead, our aim is to present the most important facts, to point to a number of unresolved puzzles, and to present an outline of a coherent story that is consistent with the facts. As far as the decline in per capita calorie consumption is concerned, one plausible hypothesis, on which much work remains to be done, is that while real incomes and real wages have increased (leading to some nutritional improvement), there has been an offsetting reduction in calorie 
requirements, due to declining levels of physical activity and possibly also due to various improvements in the health environment. The net effect has been a slow reduction in per capita calorie consumption. Whatever the explanation, there is historical evidence of related episodes in other countries, for example in Britain from 1775 to 1850 , where in spite of rising real wages, there was no apparent increase in the real consumption of food (Clark et al 1995). Per capita calorie consumption also appears to have declined in contemporary China in the 1980s and 1990 s (a period of rapid improvement in nutrition indicators such as height and weight) (see Du et al 2002 and Meng et al 2009).

One of our main points is that just as there is no tight link between incomes and calorie consumption, there is no tight link between the number of calories consumed and nutritional or health status. Although the number of calories is important, so are other factors, such as a balanced diet containing a reasonable proportion of fruits, vegetables, and fats (not just calories from cereals), and various determinants of the need for and retention of calories, including activity levels, clean water, sanitation, hygiene practices, and vaccinations. Because of changes in these other factors, the fact that people are increasingly moving away from a diet that is heavy in cereals

Table 1: Mean Per Capita Consumption of Calories, Protein, and Fats (per day)

\begin{tabular}{|c|c|c|c|c|c|c|c|}
\hline \multirow[b]{2}{*}{ Year } & \multirow[b]{2}{*}{ Round } & \multicolumn{2}{|c|}{ Calories (kc) } & \multicolumn{2}{|c|}{ otein (gms) } & \multicolumn{2}{|c|}{ Fats (gms) } \\
\hline & & Rural & Urban & Rural & Urban & Rural & Urban \\
\hline 83 & 38 & 2,240 & 0 & 63.5 & 58.1 & 27. & 37.1 \\
\hline 38 & 43 & 2,233 & 2,095 & 63.2 & 58.6 & 28.3 & 39.3 \\
\hline & 50 & $2,1 J 3$ & 2,073 & 60 & 57.7 & 31 & \\
\hline $99-2$ & 55 & 2,148 & & & 58 & 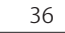 & \\
\hline $2000-01$ & 56 & 2,08 & 2,027 & 56.8 & 55.3 & 34.6 & 46.1 \\
\hline 02 & 57 & 2,0 & ,982 & 54.8 & 54.2 & 33.6 & 46.1 \\
\hline $200<2<1$ & 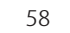 & 2,025 & & 53.4 & 54.9 & 34.7 & 47 \\
\hline 00 & 59 & 2,106 & & $=0$ & 55.5 & 36.4 & 46.7 \\
\hline 004 & 60 & 2,087 & 036 & 56.9 & 55.9 & 35.5 & 46. \\
\hline 004-05 & 61 & 2,047 & 2,021 & 55.8 & 55.4 & 35.4 & 47.4 \\
\hline
\end{tabular}

Source: Authors' calculations from NSS data. Nutrients are calculated, following the NSS practice, by multiplying reported quantities (purchased, grown, or received outside the market) by a set of nutrient conversion factors. With minor qualifications, these conversion factors (available in Gopalan et al 1980) are fixed. Appromixations are required from time to time to deal with various loose ends in the data, such as "outliers" (e g, implausibly high consumption levels), nutrient conversion for composite commodity items listed in value rather than quantity terms (eg, "other vegetables "), and meals served at home to non-household members. However, the corresponding adjustments are small, and of little consequence for our purposes. Our estimates of nutrient intakes are consistent with those presented in NSS reports, and very close to independent estimates computed for 1983 and 1999-2000 by Rekha Sharma (2006). does not imply that the nutritional status will automatically get worse. Nor should a reduction in calories associated with lower activity levels be taken to mean that Indians are currently adequately nourished; nothing could be further from the truth.

We start by documenting the decline in per capita calorie consumption (Section 2.1), as well as the state of malnutrition (Section 2.2). We then look at possible reasons for the reduction in calories (Section 3.1), and try to tease out how it fits into the general picture of economic growth and malnutrition in India (Section 3.2). Section 4 concludes.

We emphasise at the outset that our analysis covers the period up to 2006 , so that we do not discuss what has happened to calorie consumption or to nutritional status in the subsequent two years, during which there has been a marked increase in the price of food, both in India and around the world.

\section{Trends in Calorie Consumption and Nutrition}

This section discusses the decline in per capita calorie consumption and the state of malnutrition in India.

\subsection{Calories, Food, and Expenditures}

(i) Food, Calories and Cereal Calories: Table 1 shows estimates of per capita consumption of calories, protein, and fats using data from the National Sample Surveys (Nss). The estimation of calorie intake based on Nss data involves converting the reported plemented by data from the most recent "thin" rounds collected in 2000-01 (56th), 2001-02 (57th), second half of 2002 (58th), 2003 (59th), and first half of 2004 (6oth.) The per capita consumption of calories and of protein is falling in rural India, and shows no trend in urban India; this is occurring against the increase in real household per capita expenditures shown in the first two columns of Table 2 (p 44).

In rural India, household per capita calorie consumption was 2,240 calories in $1983,2,233$ in $1987-88$, and had fallen to 2,047 calories per head in 2004-05, a decline of $8.6 \%$ from 1983; urban per capita calorie consumption was only 49 calories $(2.4 \%)$ lower in 2004-05 than in 1983. Over the same period, rural (urban) per capita protein consumption fell by $12.1 \%$ (4.6\%). Only per capita fat consumption, in the last two columns, moves in the same direction as household expenditures, growing at $1.2 \%$ and $1.1 \%$ a year in rural and urban India, respectively.

The statistics in Table 1 show calories per head, and take no account of changes in household composition since 1983. In particular, fertility has fallen so that Indian households had a lower proportion of children at the end of the period. The fraction of children (ages o to 14 years) in a rural household fell from an average of 0.36 in 1983 to 0.31 in 2004-05, a decline of $14 \%$, with a larger decline, from 0.31 to 0.24 , in urban India. In consequence, if we were to compute a measure of equivalent adults, in which children counted as less than one, we would find that the number of equivalents has been growing faster than the 
number of people, so that the decline in calorie per equivalent would be even larger than the decline in calorie per person. Against this, we should note that the reduction in fertility means that a shorter span of women's lives is spent in pregnancy or lactation, during which there is a sharp increase in recommended calorie needs. But it is not clear that most women in India obtain these extra calories, and we suspect that the saving from this source is small. In what follows, we mostly stick with the per capita measures recognising that they may provide conservative estimates of a more appropriate measure of the fall in calories.

Table 2 shows that, in contrast to per capita total expenditure, and more in line with per capita calorie consumption, there has been no real increase in per capita food expenditure, particularly after 1987-88. The estimates of real food expenditure are constructed by dividing food expenditure per capita by a price index of food, here the food components of the CPIAL and CPIIw. We have

\begin{tabular}{|c|c|c|c|c|c|c|}
\hline \multirow[b]{2}{*}{ Year } & \multirow[b]{2}{*}{ Round } & \multicolumn{2}{|c|}{$\begin{array}{l}\text { PerCapita Household } \\
\text { Expenditure at } \\
\text { 50th Round Prices }\end{array}$} & \multicolumn{2}{|c|}{$\begin{array}{c}\text { d Per Capita Food } \\
\text { at 50th Round } \\
\text { Prices } \\
\end{array}$} & $\begin{array}{l}\text { 50th Round } \\
\text { Rupees Per } \\
\text { 1,000 Calories }\end{array}$ \\
\hline & & Rural & Urban & Rural & Urban & $\begin{array}{ll}\text { Rural } & \text { Urban } \\
\end{array}$ \\
\hline 1983 & 38 & 251.3 & 400.8 & 167.5 & 237.3 & $\begin{array}{ll}74.7 & 117.7\end{array}$ \\
\hline 1987-88 & 43 & 278.1 & 425.4 & 182.5 & 244.8 & 79.5115. \\
\hline 1993-94 & 50 & 281.4 & 458.3 & 181.5 & 247.7 & 82.9 \\
\hline 1999-2000 & 55 & 306 & $521.4 \quad 1$ & 184.3 & 252.5 & $\begin{array}{ll}85.6 & 124.2\end{array}$ \\
\hline 2000-01 & 56 & 316.8 & 540.61 & 186.4 & 244.3 & $87.1 \quad 125.7$ \\
\hline 2001-02 & 57 & 311.7 & $526.3 \quad 1$ & 181.8 & 237.6 & 87.4 \\
\hline $2002(2)$ & 58 & 322.8 & $551.4 \quad 1$ & 186.2 & 246.4 & $89.7 \quad 119.6$ \\
\hline 2003 & 59 & 328.5 & 545.21 & 185.6 & 242.2 & $\begin{array}{ll}88.4 & 120.9\end{array}$ \\
\hline 2004(1) & 60 & 331.6 & 548.5 & 188 & 244 & $88.1 \quad 119.8$ \\
\hline 2004-05 & 61 & 318.3 & $530.4 \quad 1$ & 184.1 & 243.7 & $89.1 \quad 121.3$ \\
\hline \multicolumn{7}{|c|}{$\begin{array}{l}\text { Source: Authors' calculations from NSS data. PCE (household total } \\
\text { expenditure per capita) deflated by the CPIAL or CPIIW scaled } \\
\text { to be unity in the } 50 \text { th round. Per capita food is mean per capita } \\
\text { expenditure on food deflated by the food components of the CPIAL } \\
\text { and CPIIW, scaled to be unity in the 50th round. Rupees per } 1,000 \\
\text { calories is calculated by dividing, for each household, per capita food } \\
\text { expenditure by per capita calories, averaging over households, and } \\
\text { then deflating by the food components of the CPIAL and CPIIW. }\end{array}$} \\
\hline
\end{tabular}

calories from cereals fell by 295, some of which was offset by increases in calories from other foods, so that the reduction in total calories was 193 (Table 1). Per capita cereal calories also fell in urban areas, by 156 calories, essentially all of which was offset by an increase in calories from other sources.

The decline in per capita calorie consumption has been previously noted in the Indian literature including, without any attempt to be exhaustive, Rao (2000, 2005), National Sample Survey Organisation (2001), Palmer-Jones and Sen (2001), Patnaik (2004, 2007), Radhakrishna, Rao, Ravi, and Reddy (2004), Meenakshi and Viswanathan (2005), Radhakrishna (2005), Ray and Lancaster (2005), Sharma (2006), Kumar, Mruthyunjava, and Dey (2007) and Suryanarayana and Silva (2007). Utsa Patnaik's two papers have been particularly influential in drawing wide attention to the decline in this aspect of nutrition, especially the fall in per capita calories from cereals. Sharma (2006) shows, based on a comalso tried the survey-based food price indexes calculated in Deaton (2008b); these show substantially more food price inflation in the last few surveys and thus even lower per capita food expenditure in 2004-05. There is also uncertainty regarding a possible overstatement of food expenditures in 1999-2000 associated with the unique questionnaire design for that survey (see Deaton and Kozel (2005a) for a summary of the literature). Even so, the real value of per capita food expenditure in 2004-05 is essentially unchanged from its level in the late 1980s. Any difference between the trend in real food expenditure and the trend in calories is a consequence of a switch in the composition of foods towards foods with lower or higher calories per rupee. That this effect has been so modest is itself something of a puzzle; we would expect rising real incomes to generate a switch, for example, from cereals to fats and sugar, from cheap calories to more expensive ones. The last columns of Table 2 show, in constant 1993-94 prices, how much the average rural and urban household paid for each 1,0oo calories consumed (these figures should not be confused with calorie price indexes - these are discussed further on). If people bought the same pattern of goods over time, this would remain constant, but it will increase if people move away from goods that provide cheap calories - such as cereals - towards goods that provide more expensive calories - such as edible oils, milk products or meat. These numbers show a modest increase in real price per calorie in the rural sector, consistent with the fall in calories and flat real food expenditure, but essentially no change in the urban sector, certainly since 1993-94. We shall return to these numbers below.

Table 3 shows that the consumption of calories from cereals has fallen even more rapidly than have calories from all foods as shown in Table 1. From 1983 to 2004-05, rural per capita parison of NSs data for 1983 and 1999-2000, that the decline of food intake is not confined to calories or proteins, but also applies to many other nutrients (fat being the main exception, as mentioned earlier).

(ii) Expenditure, Poverty, and Distribution: Tables 1 and 2 show that the decline in per capita calorie consumption has been accompanied by an increase in real average household per capita expenditure. While not all groups have shared in this equally, Table 4 ( $p$ 45) shows that there has been some growth of per capita expenditure at all percentiles of the expenditure distribution. The numbers in the table are computed by calculating the percentiles of per capita expenditure in the 38 th, 5oth, and 61st rounds (whose measures of expenditure are comparable) and then calculating the annual growth rates - in real terms - from one period to the next. Growth for these households was somewhat

\begin{tabular}{|c|c|c|c|}
\hline Year & Rural & Urban & All India \\
\hline 1983 & 1,681 & 1,303 & 1,597 \\
\hline $1987-88$ & 1,648 & 1,296 & 1,569 \\
\hline 1993-94 & 1,533 & 1,231 & 1,458 \\
\hline 1999-2000 & 1,455 & 1,200 & 1,392 \\
\hline 2000-01 & 1,422 & 1,161 & 1,357 \\
\hline 2001-02 & 1,391 & 1,130 & 1,330 \\
\hline $2002(2)$ & 1,381 & 1,137 & 1,318 \\
\hline 2003 & 1,412 & 1,142 & 1,345 \\
\hline $2004(1)$ & 1,419 & 1,165 & 1,357 \\
\hline 2004-05 & 1,386 & 1,147 & 1,326 \\
\hline
\end{tabular}

faster up to 1993-94 than in the 11 years afterwards. Growth was also somewhat more equitable in the earlier period, with the lower percentiles growing more rapidly than the higher percentiles (rural) or at about the same rate (urban) while in the later period, after 1993-94, growth rates were higher in the higher percentiles, especially in the urban sector.

The differential growth rates between the top and the bottom of the distribution and between urban and rural indicate an increase 
in inequality after 1993-94, something that is explored in more detail in Deaton and Drèze (2002). There has, nevertheless, been a steady decline in poverty rates over the period. While there has been much controversy over measurements associated with the NSs data from 1999-2000, summarised in Deaton and Kozel (2005b), the 2004-05 survey was collected on the same basis as the 1993-94 and earlier surveys, so that there is wide acceptance of the comparability of the corresponding poverty estimates. These suggest that the rural (urban) headcount ratios declined from $46 \%$ $(41 \%)$ in 1983 to $28 \%(26 \%)$ in $2004-05$. There is no evidence in the Nss data of widespread impoverishment in India, although the decline in poverty is a good deal less than might be expected given the rapid growth of per capita GDP.

As has been widely noted, the Nss-based growth rates of per capita expenditure reported in Table 4 are difficult to reconcile with the national accounts. These suggest much higher growth rates of average consumption than the unimpressive " $1 \%$ (or so) per year" shown in the Nss data. Quite likely, there is some underestimation of consumption in the Nss data, particularly among higher-income groups, and some overestimation in the national accounts, see again the papers in Deaton and Kozel (2005b). There has been much debate on these statistical issues in recent years, but this debate has limited relevance for the central concerns of this paper. The growing discrepancy between nss data and the national accounts is not plausibly attributed to food and, as we shall see, the Nss estimates of cereal consumption (on which much of our discussion will rest) are close to the national estimates. If there is growing underestimation of total consumption in the Nss data, this would, if anything, accentuate the puzzle of calorie decline examined in this paper.

\begin{tabular}{|c|c|c|c|c|c|c|}
\hline Percentile & & 10th & 25th & 50th & 75th & 90th \\
\hline \multicolumn{7}{|l|}{ Rural } \\
\hline \multicolumn{2}{|c|}{ 1983-1993/94 } & 1.7 & 1.4 & 1.2 & 1.0 & 0.8 \\
\hline \multicolumn{2}{|c|}{ 1993/94-2004/05 } & 0.9 & 0.8 & 0.8 & 0.9 & 1.0 \\
\hline \multicolumn{7}{|l|}{ Urban } \\
\hline \multicolumn{2}{|c|}{ 1983-1993/94 } & 1.1 & 1.1 & 1.2 & 1.3 & 1.2 \\
\hline \multicolumn{2}{|c|}{ 1993/94-2004/05 } & 0.4 & 0.6 & 1 & 1.2 & 1.4 \\
\hline \multicolumn{7}{|l|}{ All India } \\
\hline \multicolumn{2}{|c|}{ 1983-1993/94 } & 1.7 & 1.4 & 1.2 & 1.1 & 1.1 \\
\hline \multicolumn{2}{|c|}{ 1993/94-2004/05 } & 0.9 & 0.8 & 0.8 & 1.0 & 1.3 \\
\hline \multicolumn{7}{|c|}{ Source: Authors' calculations from NSS data. } \\
\hline \multicolumn{7}{|c|}{$\begin{array}{l}\text { Table 5: Percentages of the Population Living in } \\
\text { Households with Per Capita Calorie Consumption } \\
\text { below 2,100 Urban and 2,400 Rural }\end{array}$} \\
\hline Year & Round & & ral & Urban & AllI & ndia \\
\hline 1983 & 38 & 66 & .1 & 60.5 & & 4.8 \\
\hline 1987-88 & 43 & & .9 & 57.1 & & 3.9 \\
\hline 1993-94 & 50 & & .1 & 58.1 & & 7.8 \\
\hline 1999-2000 & 55 & & .2 & 58.2 & & 0.1 \\
\hline 2004-05 & 61 & 79 & .8 & 63.9 & & 5.8 \\
\hline
\end{tabular}

(iii) Calorie Deficiencies and Self-Reported Hunger: When an increase in per capita expenditure is accompanied by a decrease in per calorie consumption, there will be a divergence between poverty measures that are based on real expenditures and those that are based on a calorie cutoff. Indian poverty lines were originally justified by reference to calorie norms, and at the time that the original lines were drawn, average per capita calorie consumption of rural households at the rural poverty line was 2,400 calories, and average per capita calorie consumption of urban households at the urban poverty line was 2,10o calories. But all subsequent official poverty calculations have held the lines fixed in real terms, so that the official poverty ratios have declined as the distribution of per capita expenditure has moved upwards. As has been suggested by several authors, including Palmer-Jones and Sen (2001) and Ray and Lancaster (2005), we could take the calorie intakes associated with the original lines as fixed poverty norms and compute the fraction of the population living in households whose per capita calorie consumption falls beneath 2,400 calories in the rural sector and beneath 2,100 calories in the urban sector. Such calculations are shown in Table 5. Because the distribution of per capita calories is moving to the left over time, these numbers show rising poverty rates, from two-thirds of the rural population in 1983 to four-fifths in 2004-05, and from $65 \%$ to more than $75 \%$ in India as a whole. Without understanding why per capita calories are falling despite rising per capita expenditures, it is difficult to decide what, if anything, these numbers tell us about poverty. Indeed, the basic patterns emerging from this approach, e g, in terms of inter-state contrasts, are quite counter-intuitive and difficult to square with other evidence (Mahendra Dev 2005).

The fact that calorie shortfalls (based on fixed calorie norms) are not automatically associated with self-reported hunger is shown by the evidence on the latter reported in Table 6 (p 46). Except for the 1987-88 round, the Nss consumption surveys have included a question on food adequacy. In 1983 and 1993-94, respondents were asked whether everyone in the household got "two square meals a day", while in 1999-2000 and 2004-05 the question was whether everyone in the household got "enough food every day". Table 6 shows the fractions of people who did not have adequate food (in that sense) throughout the year. There are several reasons to treat these numbers as suggestive rather than definitive: the phrasing of the question is not identical in different years, there may be translation issues, and the changes from 1983 to 1993-94 are suspiciously large in several states such as Bihar and Madhya Pradesh. Insofar as they are reliable, these figures show that the fraction of rural persons going hungry has fallen from $17.3 \%$ in 1983 to $2.5 \%$ in 2004-05. In the latest survey, only West Bengal, Orissa, Assam, and Bihar are above the national average, with Chhattisgarh and Kerala at the average. The relatively high prevalence of self-reported hunger in Kerala is somewhat puzzling and raises further questions about the interpretation of these figures. What is potentially interesting is that the four states with high levels of hunger are all located in the "rice belt" of eastern India.

It is also worth noting that self-reported food adequacy is uncorrelated with calorie shortfall (i e, whether or not a household is below the calorie norms). The correlation across rural households in 2004-05 is 0.02 , and across Nss regions and states, it is actually negative, -0.17 for regions, and -0.09 for states. This lack of correlation might be taken as casting further doubt on the validity of the hunger questions, or on the relevance of the calorie norms, or even both. However, it should be noted that hunger and calorie shortfall are not the same thing, if only because the latter, as measured here, ignores differences in calorie needs, for example those associated with variations in activity levels.

(iv) On Calorie Engel Curves: That calorie consumption should fall over time alongside an increase in total expenditure is in 
sharp contrast to what happens when we look across households at a moment of time, where there is a strong positive correlation between the two. This contrast comes from the fact that, over time, there is a downward drift of the "calorie Engel curve" that plots per capita calorie consumption against per capita household expenditure: per capita calorie consumption at a given level of per capita expenditure has steadily declined over the last 20 years. For each of the large rounds from 1983 to 2004-05, Figure 1 plots per capita calories against per capita total household expenditure (both in log terms). The top five curves are for rural India, and are moving down over time. As is to be expected from Table 1, the curve for 1987-88 is close to that for 1983. By 1993-94, the downward shift has begun in earnest, but is much larger for better-off than for worse-off households. By the end of the period, the proportional shifts are about the same at all points in the distribution. The bottom of the picture shows the urban curves - at the same level of real per capita expenditure, urban households consume fewer calories per head - and, apart from the curve for the 38 th round in 1983 which cuts across the others - there is again a steady fall in the curves over time. Note that the rural calorie Engel curve in 2004-05 is close to the urban curve in 1987-88, a point to which we shall return.

Because the Nss has changed its questionnaires over this period, the graphs in Figure 1 are subject to numerous qualifications, but we do not believe they are seriously misleading. They show that in both urban and rural sectors better-off households (at least measured by per capita expenditure) consistently consume more calories than worse-off households, at least on average. The fall in calories in Table 1 comes about because the calorie Engel curves are shifting down over time. Why they should do so in a country as poor and malnourished, as is India, will be one of our main concerns in Section 3. For the moment, note that because the calorie Engel curves do not cross (except for the 1983 urban curve), per capita consumption of calories has fallen at all levels of per capita household expenditure. This only sharpens the puzzle; it is perhaps not too hard to understand why people at the top of the expenditure distribution should consume less over time, but why those with the lowest per capita expenditures should do so is a real puzzle.

(v) Total Calories and Cereal Calories: The contrast between cross-section and timeseries is also apparent when we look at calories from cereals in Figure 2 ( $p$ 47). These curves have lower slopes than do the curves in Figure 1 because the expenditure elasticity of cereal calories is lower than the total expenditure elasticity of all calories; at the margin, a higher fraction of each rupee is spent on noncereal calories than on cereal calories. As was the case for total calories, the curves are falling through time within both rural and urban
Table 6: Percentages of Rural Households Reporting Lack of Food (India and Major States) 1983 1993-94 1999-2000 2004-05

\begin{tabular}{lrrrr}
\hline Jammu and Kashmir & 1.8 & 0 & 0.6 & 0 \\
\hline Himachal & 3.9 & 0.3 & 0.2 & 0 \\
\hline Punjab & 2.2 & 0.1 & 1 & 0.6 \\
\hline
\end{tabular}

\begin{tabular}{lllll}
\hline Uttaranchal & - & - & - & 0.5 \\
\hline
\end{tabular}

\begin{tabular}{lllll}
\hline Haryana & 1.8 & 0.6 & 1.7 & 0 \\
\hline Rajasthan & 4.2 & 1.5 & 0.2 & 0 \\
\hline
\end{tabular}

\begin{tabular}{lllll}
\hline Uttar Pradesh & 10.7 & 3.3 & 2.4 & 1.9 \\
\hline
\end{tabular}

\begin{tabular}{lllll}
\hline Bihar & 34 & 6.8 & 6.3 & 3.2 \\
\hline Assam
\end{tabular}

\begin{tabular}{lllll}
\hline Assam & 14.9 & 9.9 & 7.2 & 5.5 \\
\hline
\end{tabular}

\begin{tabular}{lllll}
\hline West Bengal & 36.5 & 14.3 & 11.3 & 11.7 \\
\hline
\end{tabular}

\begin{tabular}{lllll}
\hline Jharkhand & - & - & - & 0.6 \\
\hline
\end{tabular}

\begin{tabular}{lllll}
\hline Orissa & 35.1 & 14.2 & 7.8 & 5.9 \\
\hline
\end{tabular}

\begin{tabular}{lrrrr}
\hline Chhattisgarh & - & - & - & 2.5 \\
\hline Madhya Pradesh & 14.1 & 2.6 & 3.4 & 2.1 \\
\hline Gujarat & 3.1 & 2.2 & 0.5 & 0.3
\end{tabular}

\begin{tabular}{lllll}
\hline Gujarat & 3.1 & 2.2 & 0.5 & 0.3 \\
\hline Maharashtra & 13 & 4.4 & 2.1 & 1.1 \\
\hline
\end{tabular}

\begin{tabular}{lrrrr}
\hline Andhra Pradesh & 14.4 & 3.2 & 2.2 & 0.7 \\
\hline
\end{tabular}

\begin{tabular}{lllll}
\hline Karnataka & 17.3 & 3.9 & 1.1 & 0.3 \\
\hline
\end{tabular}

\begin{tabular}{lllll}
\hline Kerala & 17.5 & 9.4 & 3.2 & 2.5 \\
\hline
\end{tabular}

\begin{tabular}{lllll}
\hline Tamil Nadu & 17.2 & 2.8 & 1.2 & 0.1 \\
\hline
\end{tabular}

\begin{tabular}{lllll}
\hline Total & 17.3 & 5.2 & 3.6 & 2.5 \\
\hline (I)
\end{tabular}

(i) - means state did not exist, (ii) Questions not asked in the 43 rd round, (iii) The question in the 38 th and 50th rounds is "Do all members of your household get two square meals a day?" with possible responses 1 (yes, square meals a day?" with possible responses 1 (yes,
throughout the year) 2 (in some months) 3 (no). In the 55th and 61st rounds the words "two square meals a day" are replaced by "enough food every day." The table shows the fractions of people living in households where the answer was other than 1 . Note that samples are often small in the smaller states. the curves in Figures 1 and 2 are moving down over time, there are differences in the size of the shift at different points in the per capita expenditure distribution, as well as between cereal calories and all calories. In rural India, the total calorie curves shift down in a roughly parallel way, so that the percentage decline in total calories is more or less the same for the rich as for the poor. For cereal calories, the decline is much sharper among the better-off. These comparisons hold per capita household expenditure fixed, so we are defining "better-off" and "poor" in terms of fixed levels of real per capita expenditure. But it is also useful to arrange rich and poor, not by expenditure, but according to their position in the distribution. Table 7 ( $\mathrm{p}$ 47) shows, for rural India, average per capita calorie and cereal calorie consumption in the bottom decile, and for each of the four quartiles of the distribution. Because there is an increase in per capita expenditure over time, people in each decile or quartile have rising real expenditure levels, so that the downward movement of the Engel curves in Figures 1 and 2 is offset by movement up the curve. And indeed, for the bottom decile, per capita calorie 
Figure 2: Cereal Calorie Engel Curves, Rural and Urban India (1983 to 2004-05)

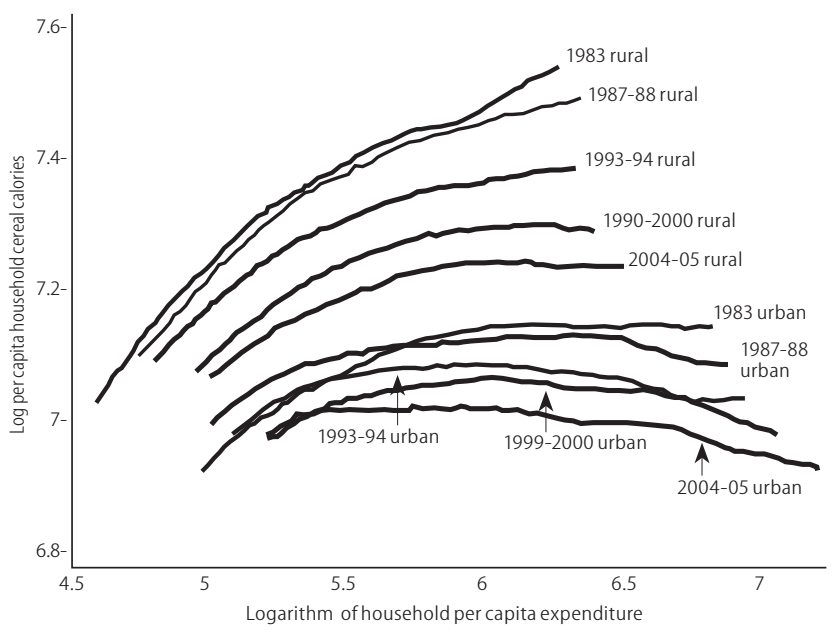

consumption has not fallen over the period. For the quartiles, even the bottom quartile, the trend is either confused or declining, so the downward shift of the Engel curves is the dominant effect, except for the bottom of the distribution.

(vii) Price Paid Per Calorie: Richer people allocate their food expenditures differently from poorer people, switching from cereals to fattier and sweeter foods, such as edible oils, meat, and sugar. The result is that households that spend more in total also spend more per calorie, which is illustrated in Figure 3 (p 48) for urban and rural households in 1983, 1993-94, and 2004-05. These curves plot the logarithm of the rupees spent per calorie divided by a general index of food prices. We can therefore imagine the changes from one period to another taking place with the price of food held constant so that movements of the curves, like movements along the curves, come from switches from cheaper to more expensive calories, or vice versa, not from changes in the price of food. Given that the calories-from-cereal Engel curves in Figure 2 are moving down over time more rapidly than the totalcalories Engel curves in Figure 1, we can expect the curves in Figure 3 to move up over time because, at any given level of total expenditure, households are reducing the relatively cheap cereal calories as a share of total calories. This is exactly what happens for rural households in Figure 3. Surprisingly, the opposite happens for urban households, in spite of the fact that urban households are also cutting down on cereal calories (Figure 2). Indeed the urban curves appear to be converging downwards towards the rural curves, though it should be noted that the overall food price indexes only account for differential inflation over time, and not for any
Table 7: Total and Cereal Calorie Consumption by Decile and Quartile of Per Capita Expenditure, Rural India (1983 to 2004-05) Bottom Bottom Second Third Top Decile Quartile Quartile Quartile Quartile

\begin{tabular}{llllll}
\hline Total Calories & & & & & \\
1983 & 1,359 & 1,580 & 2,007 & 2,328 & 3.044 \\
\hline $1987-88$ & 1,488 & 1,683 & 2,056 & 2,334 & 2,863 \\
\hline $1993-94$ & 1,490 & 1,659 & 2,000 & 2,251 & 2,702 \\
\hline $1999-2000$ & 1,496 & 1,658 & 1,978 & 2,250 & 2,707 \\
\hline 2004-05 & 1,485 & 1,624 & 1,900 & 2,143 & 2,521 \\
\hline Cereal Calories & & & & & \\
1983 & 1,150 & 1,309 & 1,589 & 1,738 & 1,974 \\
\hline $1987-88$ & 1,221 & 1,359 & 1,598 & 1,715 & 1,894 \\
\hline $1993-94$ & 1,203 & 1,316 & 1,504 & 1,591 & 1,690 \\
\hline $1999-2000$ & 1,197 & 1,289 & 1,591 & 1,509 & 1,566 \\
\hline $2004-05$ & 1,189 & 1,259 & 1,690 & 1,430 & 1,471
\end{tabular}

Source: Authors' calculations from NSS data.

increase over time in the average price paid per calorie shown in Table 2. But that mechanical result does nothing to explain this surprising behaviour among urban consumers.

(viii) Spatial Patterns of Calorie and Fat Consumption: Figures 4 (p 48) and 5 (p 49) illustrate the regional and temporal variation in per capita calorie consumption in the rural and urban sectors, respectively, comparing 1983 and 2004-05. Each area of the map is a region as defined by the Nss, an area that is a collection of districts but, in most cases, smaller than a state. The urban calorie map shows no clear pattern over time, as is to be expected from Table 1, and the rural fat maps are somewhat muted versions of the urban fat maps (these are not shown for reasons of space). Calorie consumption is highest in the north-west of India, and lowest in the south, and the successive maps show the calorie collapse with the high consumption zone retreating to the far north by 2004-05. The fat maps for the urban sector show a different pattern with fat consumption higher in the west and lower in the east, and low-fat zones retreating eastward over time. For proteins, which we do not show, the pattern is very similar to the pattern for calories, again echoing Table 1.

(ix) Is the Decline in Calories Real: Other Evidence?: It is puzzling that a country as poor and malnourished as India should react to growing prosperity without increasing real food consumption and by actually cutting back on its calorie consumption, so it is important to check that the facts are indeed correct. Table 8 (p 50) shows data on calorie consumption from an independent source, the National Nutritional Monitoring Bureau (NNMB) which periodically collects nutrition-related data in the rural areas of a number of states. Comparison with these data is also useful because the NNMB measures calories by direct weighing and recall over a short reference period (24 hours) rather than by measuring quantities of foods over a longer period and then imputing calories using tables for the calorie contents of foods.' Table 8 shows values of calorie and protein consumption that are lower than those in Table 1, most of which is explained by the fact that the NNMB covers mostly southern states where calorie consumption is relatively low; indeed, the averages from the Nss from the comparable states are quite close (see the footnote to the table). More impor tantly, we see the same declining trends as in Table 1.

Another cross-check, at least for cereal intake, comes from aggregate availability figures compiled from production data with the addition of net imports and the subtraction of addition to stocks - in practice mostly government stocks. Figure 6 (p 5o) shows the data from the Economic Survey original difference in the levels of urban and rural prices. Given that the urban curves slope up, so that better-off households pay more per calorie, and given that living standards are rising, these curves must fall over time to be consistent with the lack of any
2006-07, for cereals as well as for cereals plus pulses. The figure shows that there has been little net change in aggregate cereal (or cereal plus pulses) availability in India since independence and that there has been a clear downward trend since the early 
Figure 3: Cost Per 1,000 Calories at Constant Prices, Urban and Rural India

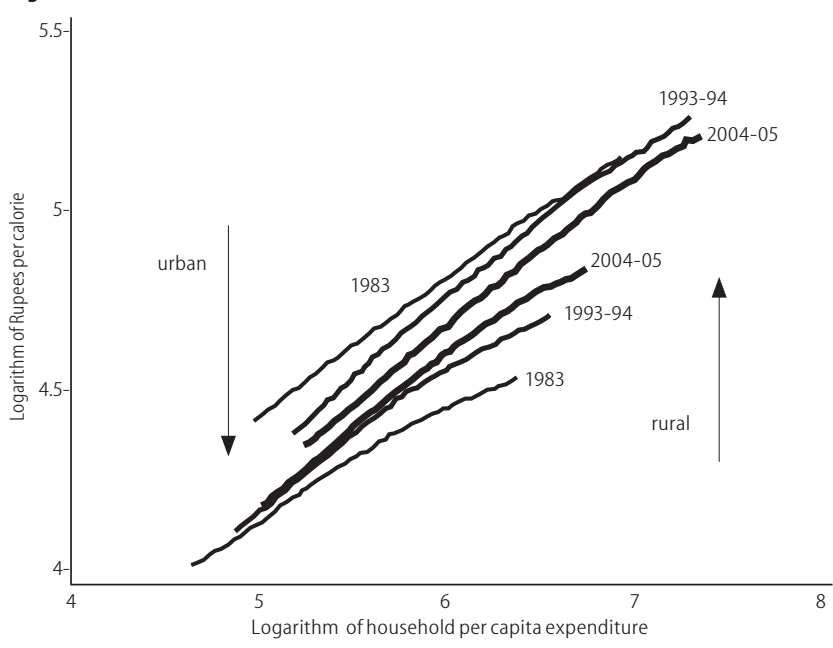

1990s, up to fluctuations that are largely attributable to the buildup and release of government stocks. Figure 6 also shows the estimates of aggregate cereal consumption from the large rounds of the Nss and, as has typically been found in the literature, at least since Minhas (1988), there is reasonably close agreement between the nss estimates and the data on availability, something that is in sharp contrast to the discrepancies between the Nss and National Accounts data on total consumer expenditure. These aggregate data are therefore consistent with the per capita calorie decline that we see in both Nss and NNMB data. There can therefore be very little doubt that the decline is real. And far from offsetting the decline in cereals, consumption of pulses has also declined.

Figure 7 (p 51) shows the disaggregation of cereal availability into three main groups: rice, wheat, and other cereals. The last group is mainly the "coarse" cereal group consisting of maize, barley, jowar (sorghum), ragi (finger millet) and bajra (pearl millet). The most notable feature here is the steady long-term decline of the coarse cereals whose consumption has fallen by a half over the last 50 years; although there have been temporary increases, the fall in coarse cereals is long established. For many years, the place of coarse cereals was taken by an increase in consumption of wheat. However, the long-run increase in wheat consumption appeared to come to an end in the late 1990s. Rice consumption began to trend downward somewhat earlier, from about the early 1990 os so that, in the last few years, there has been no increase in wheat consumption to offset the decline in the other two categories.

\subsection{Trends in Nutritional Status}

In the preceding section we have scrutinised the recent decline in per capita calorie consumption - one of the many variables that influence nutritional status. We now turn to the evidence on nutritional status itself, particularly the anthropometric evidence. Our main focus is on child nutrition.

(i) Anthropometric Measurement: For children, anthropometric indicators are typically based on age, height and weight. Three standard indicators are "height-for-age", "weight-forheight", and "weight-for-age". Low height-for-age is often referred to as "stunting", low weight-for-height as "wasting", and low weight-for-age as "underweight".

Stunting is a cumulative indicator of nutritional deprivation from birth (or rather, conception) onwards. It is relatively independent of immediate circumstances, since height does not change much in the short term. Wasting, by contrast is usually taken to be an indicator of short term nutritional status. "Weightfor-age" can be seen as a more comprehensive indicator, which captures stunting as well as wasting: both stunted and wasted children are likely to fall in the "underweight" category. Thus, if

Figure 4: Rural Per Capita Calorie Consumption, 1983 to 2004-05
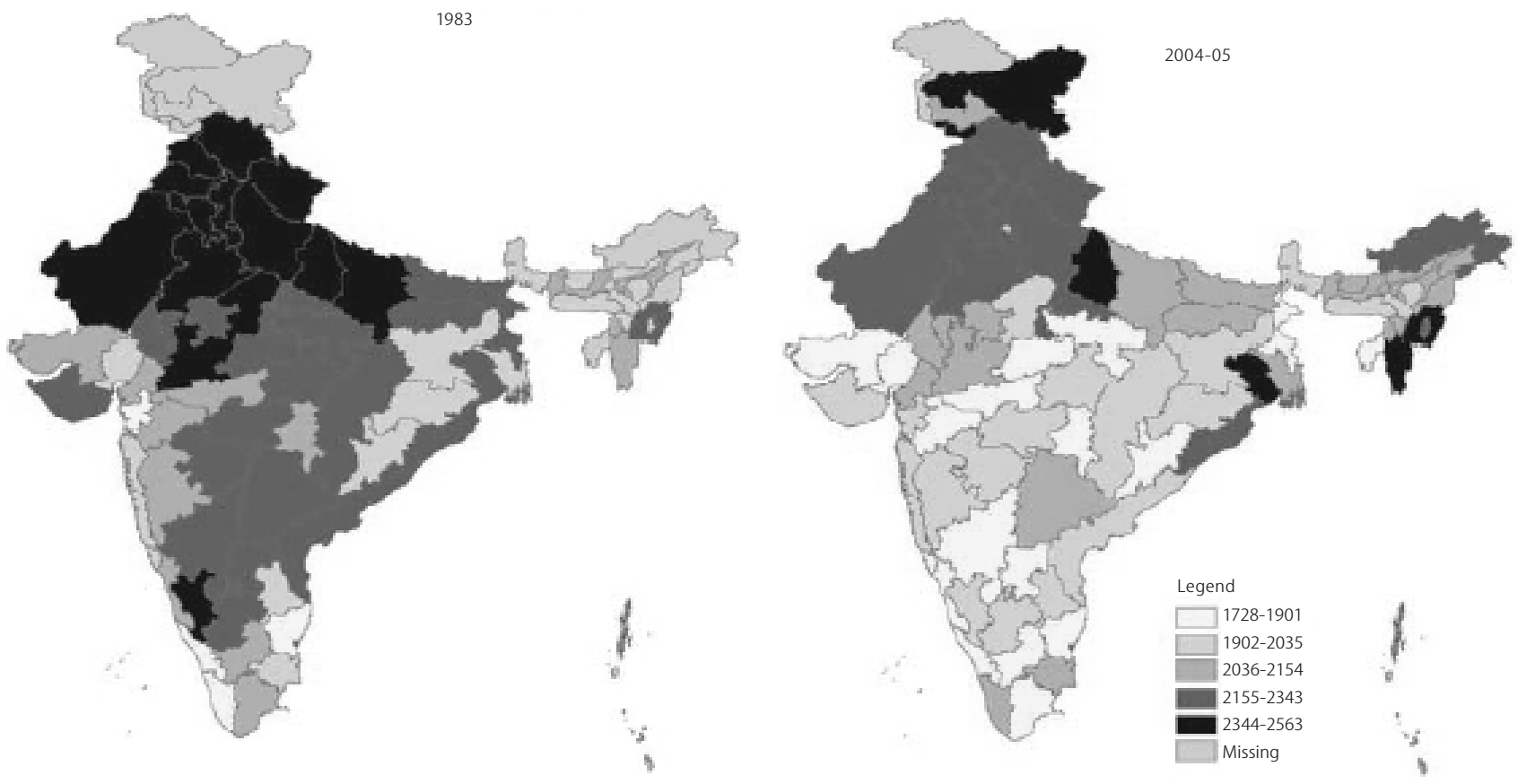


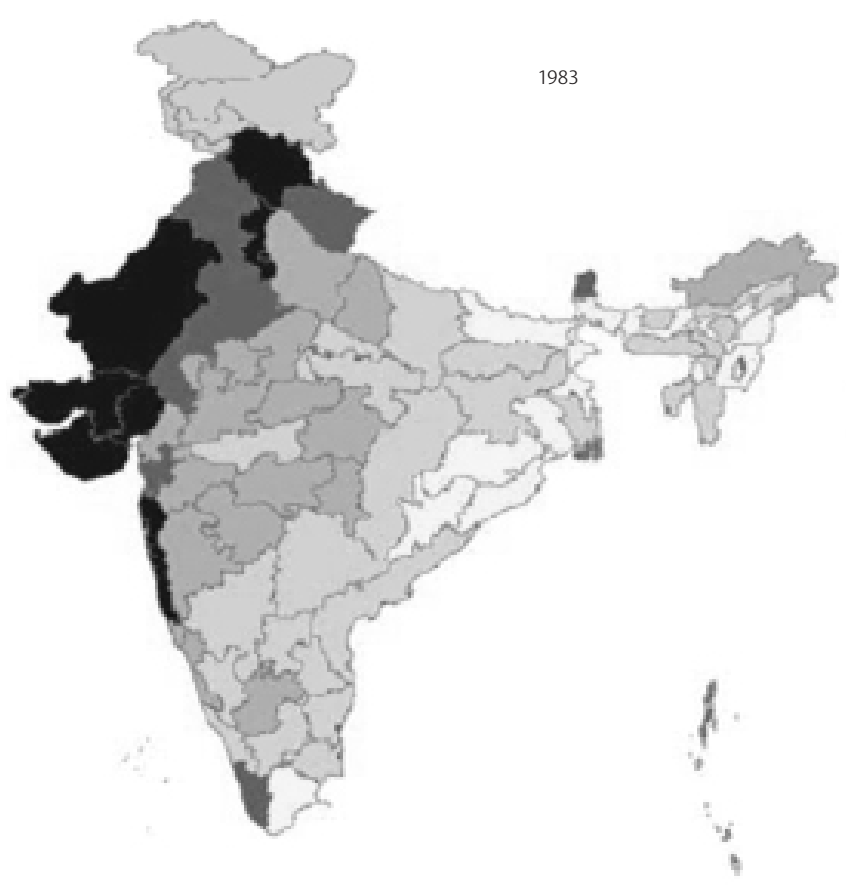

a single "summary" indicator is to be used, weight-for-age would claim special attention.

The rationale of this approach is not that there is anything intrinsically "wrong" with being short or lean. While Amitabh Bachchan's height probably served him well, Sunil Gavaskar and Sachin Tendulkar are not doing too badly either. In many cases, being short or lean is not a serious impairment. However, there is evidence that pronounced stunting or wasting in childhood is associated with serious deprivations, such as ill health, diminished learning abilities, or even higher mortality. More precisely, there is a great deal of variation in the genetic potential of individuals to be small or large, but nutritional deprivation in early life, resulting in a failure to attain one's genetic potential, is likely to cause lasting harm, see, for example, the review article by Victora et al (2008) which focuses on low and middle income countries. While genetics are important at the individual level, they are much less so - and arguably completely unimportant - at the population level, so that populations with a high fraction of people who are stunted or underweight are populations where there is evidence of nutritional deprivation. ${ }^{2}$

Children's anthropometric status is usually evaluated on the basis of international standards, which reflect the anthropometric features of children in a well-nourished reference population. ${ }^{3}$ The distribution of heights and weights in the reference population is used to set "cut-offs" below which a child would be considered stunted, wasted or underweight. A standard cut-off is "median minus two standard deviations", based on the reference population so that, for example, a child of a given age who is shorter than this cut-off would be considered stunted.

This procedure is based on the assumption that the anthropometric achievements of children in the focus population (here, India) would be much the same as in the reference population, if

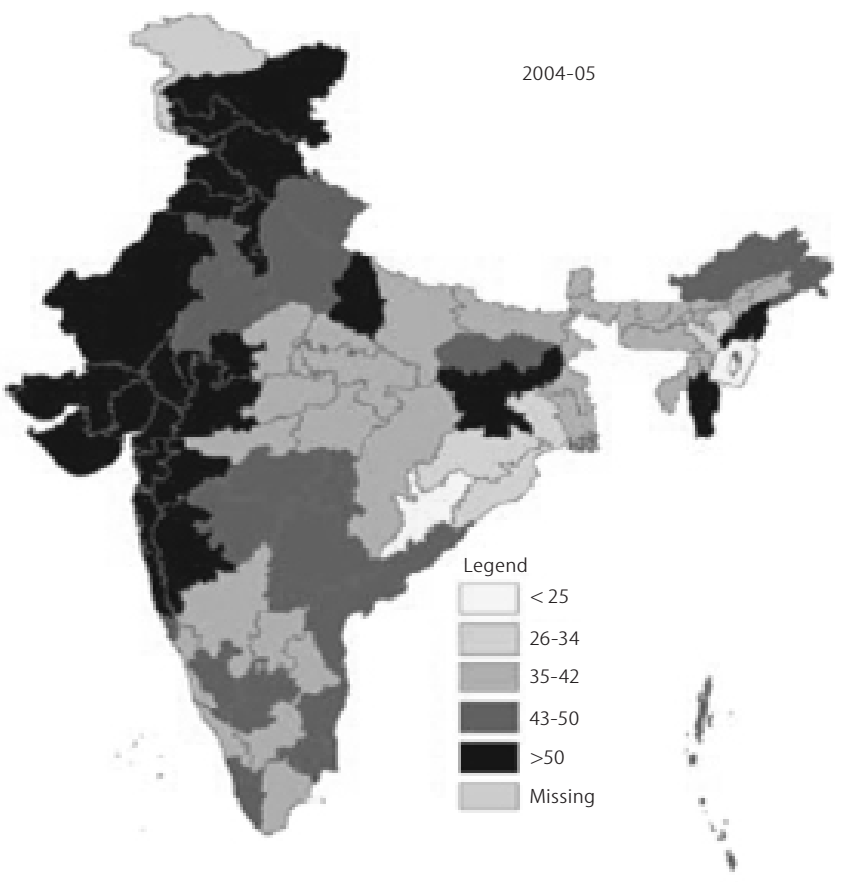

the focus children were well-nourished. In other words, anthropometric standards are similar in both populations. Since this procedure tends to be applied all over the world, it amounts to saying that there are "universal" anthropometric standards for children. We shall return to this assumption, but accept it for now.

(ii) Nutrition Status of Indian Children: There are two major sources of anthropometric data for Indian children: the NNMB at the National Institute of Nutrition, Hyderabad, and the National Family Health Survey (NFHS). Considering the former first, the NNMB surveys go back to the 1970s, but are available for nine states only: Andhra Pradesh, Gujarat, Karnataka, Kerala, Madhya Pradesh, Orissa, Maharashtra, Tamil Nadu and West Bengal (hereafter the "NNMB states"). ${ }^{4}$ In each state, the NNMB surveys cover 20 households per village in 120 villages (urban areas are excluded). From 1991-92 onwards, the NNMB sample villages are sub-samples of Nss samples. In the "repeat surveys" (1975-79, 1988-90 and 1996-97), the 120 sample villages consist of 90 villages from the previous survey and 30 "new" villages. The repeat surveys are meant to be fully comparable and provide perhaps the safest basis for assessing nutrition trends from NNMB data, at least if height selective out-migration is not important. In Table 9 (p 52), we present indicators of child nutrition based on the repeat surveys, extended using the most recent NNMB surveys.

One difficulty with this exercise is that some states are "skipped" in some surveys: specifically, West Bengal in 1975-79 and 1988-90, and Madhya Pradesh in 1996-97. Further, it is not possible to construct a consistent series of aggregate figures for the remaining seven states from the NNMB reports, due to missing data. However, weight-for-age data are available state-wise for each survey year from the NNMB reports, and close scrutiny of these data shows that omission of one of these two states makes 
Table 8: Calorie and Protein Consumption from

National Nutritional Monitoring Bureau

\begin{tabular}{lrrrrr}
\hline & \multicolumn{5}{c}{ Rural Per Capita Consumption (nine states) } \\
\cline { 2 - 6 } & $1975-79$ & $1988-90$ & $1996-97$ & $2000-01$ & $2004-05$ \\
\hline Energy & 2,340 & 2,283 & 2,108 & 1,954 & 1,907 \\
\hline Protein & 62.9 & 58.4 & 53.7 & 50.7 & 48.8
\end{tabular}

Andhra Pradesh, Gujarat, Karnataka, Kerala Madhya Pradesh, Maharashtra, Orissa Tamil Nadu, and West Bengal. 1988-90 and 1996-97 estimates exclude Madhya Pradesh and West Bengal. The 2004-05 figures exclude Gujarat. NSS estimates for the comparable states in nearby years are as follows: calories, 2,131 (1983), 2,139 (1987-88), 2,076 (1993-94), 2,020 (1999-2000), 1,960 (2004-05); protein, 57.5 (1983), 57.0 (1987-88), 54.7 (1993-94), 52.7 (1999-2000), and 50.8 (2004-05).

Source: National Nutrition Monitoring Bureau (1991, 1996a, 1996b, 1997, 1999, 2000, 2002, 2005, 2006), and authors' calculations from NSS data.

little difference to the aggregates. Thus, the aggregate figures presented in the NNMB reports (for nine states, with Madhya Pradesh "missing" in one year and West Bengal missing in two years) are good enough for the purpose of assessing broad nutrition trends. These are the figures shown in Table 9 for child nutrition, and later in Table 12 (p 53) for adult nutrition.

The child nutrition indicators presented in Table 9 point to a steady retreat of severe undernourishment during the last 30 years or so. For instance, between 1975-79 and 2004-05, there have been reductions of around $50 \%$ in the prevalence of severe undernutrition (measurement below three standard deviations of the median of the reference distribution), whether one looks at weight-for-age (37\% of the child population to $18 \%$ ) or height-forage $(53 \%$ to $25 \%))^{5}$ The retreat of severe undernourishment can also be seen from the sharp decline over the same period in the prevalence of clinical signs of nutritional deficiency, such as marasmus and oedema. These findings are consistent with the decline of self-reported hunger presented earlier in Table 6.

Having said this, the overall levels of child undernutrition in India (including not only severe but also "moderate" undernourishment) are still very high, both in absolute terms as well as relative to other countries. Even today, close to half of all Indian children are underweight, and about half suffer from anaemia. These are appalling figures, which place India among the most "undernourished" countries in the world. According to the 2007 World Development Indicators, only two countries have higher proportions of underweight children (based on the same standards): Bangladesh and Nepal. While Pakistan and Sri Lanka have somewhat lower levels of child undernutrition, the whole south Asian region stands apart from the rest of the world in this respect. In particular, child undernutrition is much higher in south Asia (48.5\% underweight in 1999) than in sub-Saharan Africa (29.6\% underweight in 2005), although the most undernourished countries in both regions fare much the same, as Table 10 (p 52) indicates.

NFHS data corroborate these basic patterns, with some qualifications. Three rounds of the NFHs are available so far. They were conducted in 1992-93, 1998-99 and 2005-06. We shall refer to them as "NFHS-1", "NFHS-2" and "NFHS-3", respectively. As far as levels of undernutrition are concerned, NNMB and NFHS data are broadly consistent (for rural areas). For instance, both NNMB and NFHS place the proportion of underweight children at around half in the latest year for which data are available (2004-05 and 2005-06, respectively). However, there are significant differences between these two sources as far as trends in child nutrition are concerned. (iii) Recent Trends in Child Nutrition: Until recently, trends in anthropometric indicators presented a reasonably clear picture. Whether one looked at, say, the heights or weights of children, or the "Body Mass Index" (вмI) of adults, the dominant pattern was one of sustained improvement. We have already noted some of these trends in the preceding section, as they emerge from NNMB data (Table 9). The first two rounds of the National Family Health Survey (NFHS-1 and NFHS-2) appeared to be broadly consistent with the NNMB data in this respect. For instance, according to NFHS data, the proportion of underweight children declined from $52 \%$ in $1992-93$ to $47 \%$ in $1998-99$ (International Institute for Population Sciences 2000a, p 267). NNMB data suggest a similar rate of decline - about one percentage point per year in the 199os (Table 9). As discussed below, BMI data for Indian adults also show a sustained improvement over time, albeit from levels of height and weight that were (and still are) among the lowest in the world.

However, the most recent data, from the third round of the National Family Health Survey (NFHS-3), tell a different story. According to NFHS-3, the proportion of underweight children in 2005-06 (using the same standards as in NFHS-1 and NFHS-2) was $46 \%$ - virtually the same as in 1998-99. This apparent "stalling" of nutritional improvement came as a rude shock when these numbers were published in late 2006, at a time of widespread euphoria about India's rapidly growing economy. If correct, this statistic raises serious questions about what is currently holding up the progress of child nutrition in India.

The NFHS-3 data on weight-for-age, however, are not quite conclusive in this respect, for several reasons. First, the evidence on weight-for-age needs to be read together with other indicators of

Figure 6: Availability of Cereals ( 1950 to 2004, gms per capita per day)

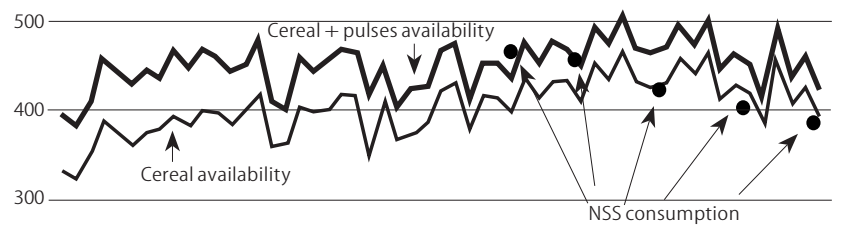

200

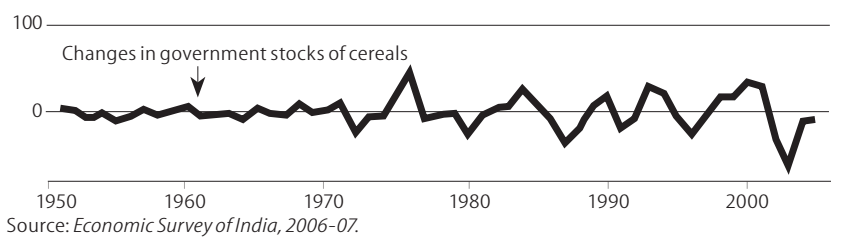

child nutrition, such as height-for-age and weight-for-height. A fuller picture of NFHS-3 data (and the corresponding NFHS-2 estimates) is presented in Table 11 ( $\mathrm{p}$ 53), which shows that while the proportion of underweight children remained virtually unchanged between 1998-99 and 2005-06, there was a significant decline in stunting (from 51 to $45 \%$ ), and a small increase in wasting (from 20 to 23\%). The stagnation of underweight indicators can be thought of as an averaging of the opposite movements of stunting and wasting but it is far from clear why wasting 


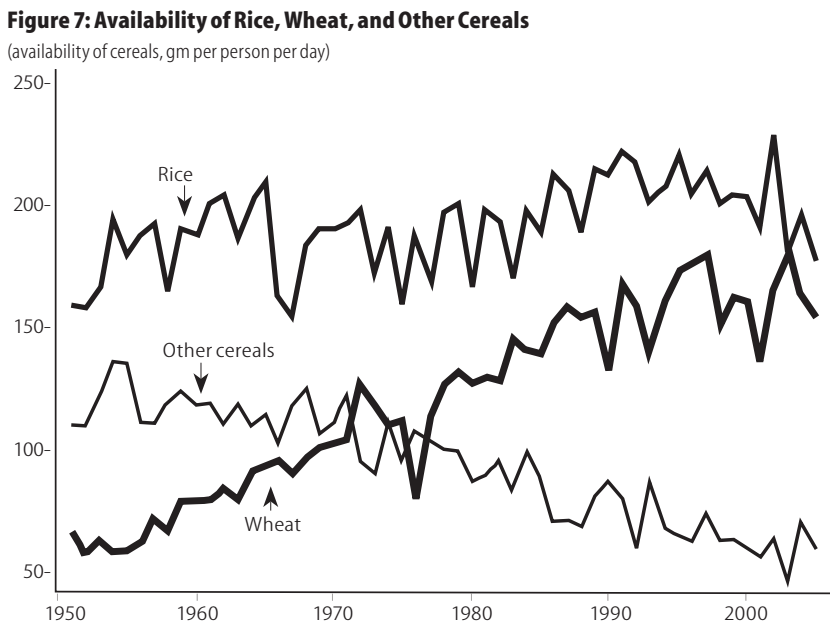

Source: Ministry of Agriculture.

should increase while stunting goes down. Perhaps the decline of stunting in this period reflects continued improvements in maternal health, themselves related to nutritional improvements that occurred 20 or 30 years ago (when today's mothers were children). The increase in wasting, for its part, is quite puzzling, and it is difficult to come to any firm conclusion without a better understanding of these opposite trends.

Second, there are also contrasting indications from NFHs and NNMB data. Indeed, the latest NNMB survey, conducted in 2004-05, suggests a continuation of the earlier decline of undernutrition as reflected in weight-for-age data, in contrast with the "stalling" pattern in the NFHs data (Table 9). Further, this decline is associated with a sharp decline in wasting, and some increase in stunting - almost the "reverse" of the NFHs trends on these indicators. ${ }^{6}$

Third, there is a possible issue of comparability between NFHS-2 and NFHS-3 data (on this see also Rajan and James 2008). This is not immediately obvious from anthropometric data, but other indicators give reason for doubt in this respect. For instance, the NFHS surveys suggest that there has been a decline of school attendance between 1998-99 and 2005-06, even though there is much independent evidence of major increases in school attendance during that period, from the Nss (Sankar 2007) and other sources (e g Samson et al 2009). There are also inconsistencies between NFHS-2 and NFHS-3 in the measurement of adult height, which we discuss in the next subsection. In short, the "crisis" signals emerging from NFHS-3 data on weight-for-age are yet to be corroborated, and further research (and evidence) is required to make sense of these contrasting indications on recent nutrition trends.

Having said this, even if we ignore the most recent crisis signals and take a somewhat longer view (for which there is evidence of sustained improvement, as mentioned earlier), the progress of nutrition indicators in India seems to be undistinguished, given the country's high rates of economic growth from the early 199os onwards. To illustrate the point, one recent study of international data concludes that the rate of decline of child undernutrition (based on weight-for-age) tends to be around half of the rate of growth of per capita GDP (Haddad et al 2003). If this rough benchmark can be applied to India, which grew at $4.2 \%$ a year from 1990 to 2005, we would have expected the proportion of underweight children to have declined by $2.1 \%$ a year, or by about $27 \%$ since 1990 . But the actual decline was only about $20 \%$, according to NNMB data for nine states (Table 9), and much less (barely 10\%) according to NFHS data. Over the longer period, from 1980 to 2005, which includes the earlier decade of somewhat slower growth, the predicted decline is $38 \%$, and the actual improvement was $29 \%$. As we have already noted, the growth rates of per capita consumption in Table 4 are a good deal lower than the measured growth rates of per capita GDP, almost certainly because of measurement errors on both sides, and it is possible that the growth rate of per capita GDP is somewhat exaggerated, and the nutritional improvements are close to what might be expected based on the international benchmark. For example, a growth rate of $3 \%$ a year from 1990 to 2005 , which is more than twice the growth rates recorded in Table 4, would be consistent with the $20 \%$ improvement in Table 9. Of course, there is little comfort in saying that the Indian rates of nutritional improvement can be reconciled with international experience by discounting the estimates of economic growth. If India is indeed growing as fast as is claimed, there are important requirements of better nutrition that are being held up, and this is in spite of sustained recent improvements in other important determinants of child nutrition, such as maternal education and the availability of safe water.

The contrast between India and China is also of some interest in this context. There is evidence of a steady growth in the heights of Chinese children in recent decades, not only during the period of fast economic growth that followed the "economic reforms" of the late 1970s, but also before that. For instance one recent study reports that, in a representative sample of

Figure 8: Average Heights of Indian Men and Women by Age

Women's mean height

Men's mean height
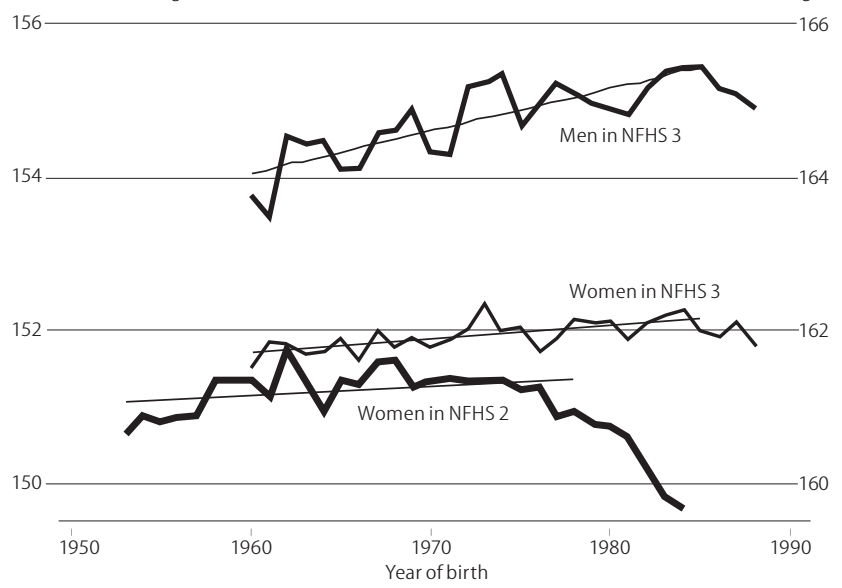

Chinese children aged 2-5 years, the average increase in height between 1992 and 2002 was $3 \mathrm{~cm}$ in rural areas (for both boys and girls), and even higher in urban areas $(3.6 \mathrm{~cm}$ and $3.8 \mathrm{~cm}$ for boys and girls, respectively); see Yang et al (2005). ${ }^{7}$ And, according to an earlier study, "the average heights of Chinese children between the ages of 7 and 14 years increased by approximately $8.04 \mathrm{~cm}$ between 1951-58 and 1979" (Harris 2000 based on Piazza 1984). 
Table 9: Child Nutrition Indicators (1975-79 to 2004-05, rural) Proportion (\%) of Undernourished Children ${ }^{\mathrm{a}} \quad$ Percentage Decline \begin{tabular}{lllllll}
$1975-79$ & $1988-90$ & $1996-97$ & $2000-01$ & $2004-05$ & (1975-79 to 2004-05) \\
\hline
\end{tabular}

\begin{tabular}{llllllll}
\hline $\begin{array}{l}\text { Weight-for-age } \\
\text { Below 2 SD }\end{array}$ & 77 & 69 & 62 & 60 & 55 & 29 \\
\hline Below 3 SD & 37 & 27 & 23 & 21 & 18 & 51
\end{tabular}

\begin{tabular}{lllllll} 
Below 3 SD & 37 & 27 & 23 & 21 & 18 & 51 \\
\hline $\begin{array}{l}\text { Height-for-age } \\
\text { Below 2 SD }\end{array}$ & 79 & 65 & 58 & 49 & 52 & 34 \\
\hline Below 3 SD & 53 & 37 & 29 & 26 & 25 & 53 \\
\hline
\end{tabular}

Weight-for-height

Below 2 SD 18

Below 3 SD

$\begin{array}{lll}18 & 20 & 19 \\ 2.9 & 2.4 & 2.5\end{array}$

19

$23 \quad 15$

Prevalence of nutritional deficiency signs (\%)

\begin{tabular}{lcccccc} 
Oedema & 0.4 & 0.1 & 0.1 & 0 & 0 & 100 \\
\hline Marasmus & 1.3 & 0.6 & 0.1 & 0.2 & 0 & 100 \\
\hline Bitot spots & 1.8 & 0.7 & 0.7 & 0.8 & 0.6 & 67 \\
\hline Angular stomatitis & 5.7 & 5.7 & 2.1 & 1.4 & 0.8 & 86 \\
\hline
\end{tabular}

a Based on NCHS standards (see Table 11).

b Difference between the 1975-79 and 2004-05 figures, as a ratio of the former.

Source: National Nutrition Monitoring Bureau (1991, 1999, 2002, 2006). All figures pertain to children aged 1 to 5 years in rural areas. These figures apply to the nine "NNMB states": Andhra Pradesh, Gujarat, Karnataka, Kerala, Madhya Pradesh, Maharashtra, Orissa, Tamil Nadu, West Bengal. Data for 1975-79 and 1988-90 exclude West Bengal; data for 1996-97 exclude Madhya Pradesh. See text for further discussion.

NNMB data suggest much slower growth rates and heights of Indian children. For instance, in the "NNMB states" the increase in children's heights between 1975-79 and 2004-05 was a little below two $\mathrm{cm}$ per decade at age three, and barely one $\mathrm{cm}$ per decade at age five. ${ }^{8}$ The NNMB data also suggest that the growth rates of heights and weights were particularly slow in the later part of this period, with, for instance, very little growth in the heights of children at age five between 1996-97 and 2004-05.

Here again, however, there are significant differences between NNMB and NFHS data. For instance, a comparison between NFHS-1 and NFHS-3 suggests that children's height at age three increased by about $2.5 \mathrm{~cm}$ per decade between 1992-93 and 2005-06, which looks much closer to the Chinese rates of increase. Further work is required to reconcile these different sources, and to assess the comparative progress of nutrition indicators in India and China.

(iv) Adult Weights and Heights: Recent nutrition trends can be further scrutinised from available data on adult weights and heights. A useful starting point is the BMI, defined as the ratio of weight (in kilos) to the square of height (in metres). Table 12 presents the proportion of men and women with BMi below 18.5 (a standard cut-off conventionally associated with "chronic energy deficiency") in the nine NNMB states. The proportion of individuals with low BMI, like that of underweight children, declined steadily during the last 30 years or so. In spite of this, Indian adults today (like Indian children) have some of the highest levels of undernutrition in the world, with $36 \%$ of adult women suffering
Table 10: Countries with the Highest Levels of Child Undernutrition (1996-2005) Country Proportion (\%) of Children

with Low "Weight for Age"

Nepal 48.3

\begin{tabular}{ll}
\hline Bangladesh & 47.5 \\
\hline India & 46.7 \\
\hline Timor-Leste & 45.8
\end{tabular}

Yemen 45.6

\begin{tabular}{ll}
\hline Burundi & 45.6 \\
\hline
\end{tabular}

\begin{tabular}{ll}
\hline Madagascar & 41.9
\end{tabular}

Sudan 40.7

Lao (People's Dem Rep) $\quad 40.4$

Niger 40.1

\begin{tabular}{ll}
\hline Eritrea & 39.6
\end{tabular}

Afghanistan 39.3

Source: World Development Indicators 2007. Figures apply to the most recent year for which data are available within the reference period. There is a significant margin of error for individual countries. from low BMI (rising to well over 40\% in several states). ${ }^{9}$ Among 23 countries of sub-Saharan Africa for which comparable data are available from the Demographic and Health Surveys, only one (Eritrea) is doing worse than India in this respect (Table 13, p 54). In fact, the proportion of adult women with low BMI is above $20 \%$ interest to compare their growth with other countries, as well as to look at differences between Indian states. Data from the China Health and Nutrition Survey between 1989 and 2004 show that Chinese adults, both men and women, have been gaining height at around one $\mathrm{cm}$ per decade. Not only have Chinese men grown taller at twice the rate of Indian men, but 
Table 11: Trends in Child Nutrition - NFHS Data

Proportion (\%) of Children under the Age of Three Years Who Are Undernourished

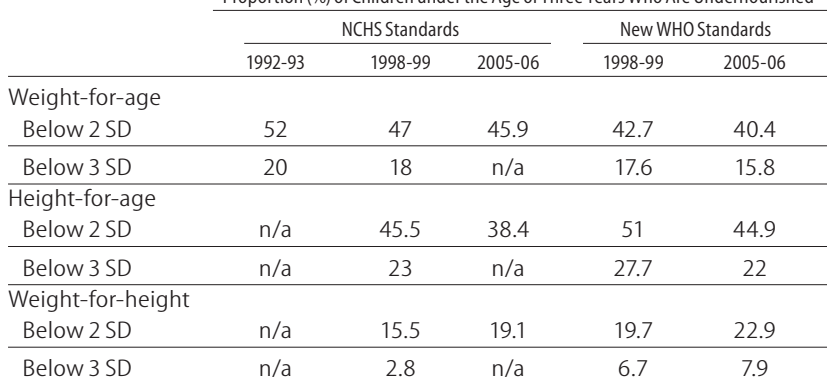

(1) The National Center for Health Statistics (NCHS) standards, recommended until 2006 by the World Health Organisation (WHO), were used in NFHS-1 and NFHS-2, and are also used by the National Nutrition Monitoring Bureau (see Table 9). The new WHO Child Growth Standard, released in 2006 (see WHO 2008), are used in the NFHS-3 report (IIPS 2007a), although the provisional NFHS-3 "Fact Sheets" (IIPS 2007b, 2007c) present figures based on the NCHS standards that appear to be comparable with the NFHS-1 and NFHS-2 figures; these are shown here in the middle column. (2) The NFHS-2 figures are based on the last two children under three years of age of the sample women (ever-married women in the age group of $15-49$ years). For purposes of comparability, the NFHS-3 figures presented in the last column focus on the same group.

Source: International Institute for Population Sciences (2000), pp 266-67, and International Institute for Population Sciences (2007a), p 274. The 2005-06 figures based on NCHS standards are taken from the "National Fact Sheet" (International Institute for Population Sciences 2007b).

Table 12: Nutrition Status of Indian Adults, 1975-79 to 2004-05 (Body Mass Index)

\begin{tabular}{|c|c|c|c|c|c|c|}
\hline & \multicolumn{5}{|c|}{ Proportion (\%) of Adults with Body Mass Index below 18.5} & \multirow{2}{*}{$\begin{array}{c}\text { \% Decline (1975-79 to } \\
2004-05)\end{array}$} \\
\hline & $1975-79$ & $1988-90$ & $1996-97$ & 2000-01 & $2004-05$ & \\
\hline Men & 56 & 49 & 46 & 37 & 33 & 41 \\
\hline Women & 52 & 49 & 48 & 39 & 36 & 31 \\
\hline
\end{tabular}

Sources: National Nutrition Monitoring Bureau $(1999,2002,2006)$. These figures apply to the nine "NNMB states": Andhra Pradesh, Gujarat, Karnataka, Kerala, Madhya Pradesh, Maharashtra, Orissa, Tamil Nadu, West Bengal. Data for 1975-79 and 1988-90 exclude West Bengal; data for

1996-97 exclude Madhya Pradesh. See text for further discussion.

there is no evidence in China of the differential disfavouring of women that we see in India. In this respect, other neighbouring countries also appear to be doing better than India, although not as well as China. Women in Bangladesh have been growing at about $0.24 \mathrm{~cm}$. a decade, and women in Nepal at $0.59 \mathrm{~cm}$ per decade; these data come from Demographic and Health Surveys which do not include data on men's heights, at least as yet. That the Chinese growth rates are not impossible in India is clearly shown by the data for Kerala, where men and women are growing taller at 1.29 and $1.16 \mathrm{~cm}$ per decade respectively, even faster than in China, Deaton (2008a, Table 1). Indeed, decadal rates of height increase of around one $\mathrm{cm}$ have previously been reported for a range of European countries between 1870 and 1970, Floud, Wachter, and Gregory (1990, Figure 1.7). For those born between 1950 and 1980, Scandinavians grew taller by a little less than one centimetre per decade, while southern European countries such as Spain, Portugal, and Italy, where people are shorter, were catching up with growth rates closer to two $\mathrm{cm}$ a decade (Bozzoli et al 2009). Taking all this together, the growth rates of heights in China and Kerala are in line with historical experience, while India as a whole is making much slower progress, especially but not exclusively for women.

The graphs in Figure 8 show that the data on women's heights are inconsistent between NFHS-2 and NFHS-3, with women of the same birth cohort apparently taller in the later survey. The difference between the two lines is only $0.16 \mathrm{~cm}$, but this is quite large relative to the annual growth rate and, because it happens for all dates of birth, it is clearly not attributable to random sampling error in the estimation of mean heights. (Back of the envelope calculations also suggest that this discrepancy is too large to be accounted for by height-selective maternal mortality.) We noted earlier that other questions have arisen about the NFHS-3 so there was perhaps some sampling difference between the two surveys. With a taller sample of women in NFHs-3, we would expect to see taller children - so that the reduction in stunting between the two surveys may be overstated - as well as thinner children - the children of taller women tend to have lower weight for height which would mean that the increase in wasting over the two surveys may be overstated. We can assess this using NFHs-2 by estimating the effects of mother's height on the probability of her child being wasted or stunted. But when we do so, the effects are tiny and make no difference to the trends discussed earlier; a sample of women that is 1.6 millimetres taller will have a fraction of children stunted that is $0.26 \%$ of a lower, and a fraction wasted that is $0.03 \%$ of a higher.

\section{Interpretations}

This section looks at the possible reasons for the reduction in calories and how this fits into the general picture of economic growth and malnutrition in India.

\subsection{The Calorie Decline}

(i) Food Prices: Returning to the puzzle of falling calorie intake, the first possibility to consider is that the decline was driven by an increase in food or calorie prices relative to the prices of other things. In spite of the fact that people buy food, and not calories, we can think of price indexes of food as price indexes of calories. To see this, suppose the price of food $i$ is $p_{i}$ per kilo, and its calorie content is $k_{i}$ per kilo, then the price per calorie through good $i$ is $p_{i} / k_{i}$, so that provided the calorie contents do not change over time - an issue to which we will return - calorie prices are just food prices in different units and any index of food prices can be reinterpreted as an index of calorie prices, at least for foods that have non-zero calorie content. In consequence, calories become relatively more expensive or cheaper according to whether food prices rise faster or slower than non-food prices. Figure 9 (p 55) shows the monthly ratios of food to general price indexes for the rural (CPIAL) and urban (CPIIW) sectors. All four indexes, CPIAL food, CPIAL general, CPIIW food, and CPIIW general have been scaled to be 100 in 1993-94, and are shown as ratios of food to general within sectors. In rural India, food (and therefore calorie) prices moved along with general prices from 1983 until about 200o, and then fell by a little less than $5 \%$ relative to general prices. In urban India, there was a slow secular increase in the relative price of food, by less than $5 \%$, from 1983 until the late 1990 , followed by a more pronounced decline, by more than $10 \%$, until the end of the period. In both sectors, the relative price of food was lower in 2004-05 than at the start of the period in 1983. The decline in calorie consumption cannot therefore be attributed to any increase in the relative price of food. In Deaton (2008b) one of us has argued that the food component of the CPIAL, as well as the CPIAL itself, is understated after 2000 through the use of outdated weights in the official indexes. However, there is no question about the relative decline in food prices after 200o, or about the long-term decline between 1983 and 2004-05. 
(ii) Coarse Cereal Prices: Although food prices may not have risen in general, it is conceivable that some component of food prices has risen, and in particular that the decline in coarse cereals was driven by an increase in their relative price, and that this, by itself, might go at least some way to explain the decline in cereal and in total calorie consumption. This explanation is somewhat implausible in theory, because we would expect an increase in the price of one cereal group to lead to a substitution into another cereal - in this case wheat - not to a reduction in overall calories, whose general price is falling in relative terms. It is also false on the numbers (see Table 14, $\mathrm{p} 55$ ). Rural food prices rose by 4.8 times from 1983 to 2004-05, and urban food prices by 5.2 times. The corresponding figures for coarse cereals are 3.6 times and 4.6 times, so that coarse cereals (and calories from coarse cereals) have become systematically cheaper than food (and calories from food) as a whole. Only in the period from 1993-94 to 1999-200o did the price of coarse cereals rise more rapidly than other food prices.

(iii) Impoverishment?: If it is not relative prices that are shifting the calorie Engel curves, what can be causing the calorie decline? One account, most prominently argued by Patnaik $(2004,2007)$, is that hunger and deprivation are increasing, especially in agriculture, and that people are purchasing fewer calories, particularly cereal calories, because they cannot afford to do otherwise. Some combination of falling incomes, rising prices, and rising agricultural unemployment has impoverished a substantial fraction of the rural population.

However, as discussed earlier there is little direct evidence of sustained, widespread impoverishment of the rural population in the 1980 s and 1990s. Further, the impoverishment argument jars with the fact that the decline of nutrient intakes has been proportionately larger - much larger - in the higher per capita expenditure groups (see Figures 1 and 2). There is strong evidence that these groups have enjoyed sustained increases in living standards in the 1980 s and 1990s. Clearly, something other than "impoverishment" (e g, a reduction in nutrient requirements associated with reduced activity levels or better health) needs to be invoked to explain the decline of nutrient intakes among these groups. And it is quite possible that this hidden factor, whatever it was, also played a role in the stagnation of nutrient intakes among lower income groups.

The impoverishment view also requires us to challenge some aspects of the data presented so far. In particular, it implies that the rise in real per capita expenditure in the Nss must somehow be incorrect, possibly because expenditures are overstated, price inflation understated, or some combination of the two. Or perhaps there has been a substantial widening of the income distribution, with the majority of people getting worse off, so that growth at the mean is driven only by progress at the top. But with a few minor exceptions to do with weighting, the inflation rate in the CPIAL is supported by the unit values observed in the Nss surveys. Nor is there any evidence in Table 4 that the poor are getting worse off, even if they have done less well than the average. And while the Nss expenditure figures have been robustly challenged, the general complaint and one that we endorse, at least to some extent - is that, in light of the national accounts, they appear to underestimate (rather than overestimate) the growth of per capita expenditure over time.

(iv) Sen's Argument: In an interesting paper (concerned mainly with the method of poverty measurement), Pronab Sen (2005) takes up the question of why it is that people around the current poverty line are purchasing many fewer calories than the 2,400 (rural) and 2,100 (urban) recommended allowances that played a part in the original derivation of the lines. Since the purchasing power of the poverty line has been held constant, by construction, the recommended allowances are, in principle, no less (or more) affordable than when they were established. As Sen points out, however, it is possible that the food budget has been squeezed out because "the cost of meeting the minimum non-food requirements has increased" (p 4612). To illustrate, suppose that poor households have access to schooling facilities that were not available earlier. Schooling expenses (including, say, adequate clothes for children) would become a new item on the household budget, and food expenditure may be curtailed to make room for it.

In response to this argument, Sen notes that households around the poverty line could still achieve the recommended calorie intakes within their current food budget by spending their actual food budgets, not as they do, but on the foods that yield the same number of calories per rupee as are actually purchased by people below the poverty line on average. In other words, people at the line could meet the calorie norms within their current actual food budgets if they had the same food purchasing patterns as the typical poor person. This may be a useful point to note, if food purchases below the poverty line are not of much lower quality than food purchases at the line. But it does not establish that there is no "squeeze" in the food budget.

What would be more useful to know is whether households around the poverty line can or cannot use their current expenditures on food to purchase their baseline food basket, which meets 
Figure 9: Ratio of Food to Non-Food Price (Urban and Rural)

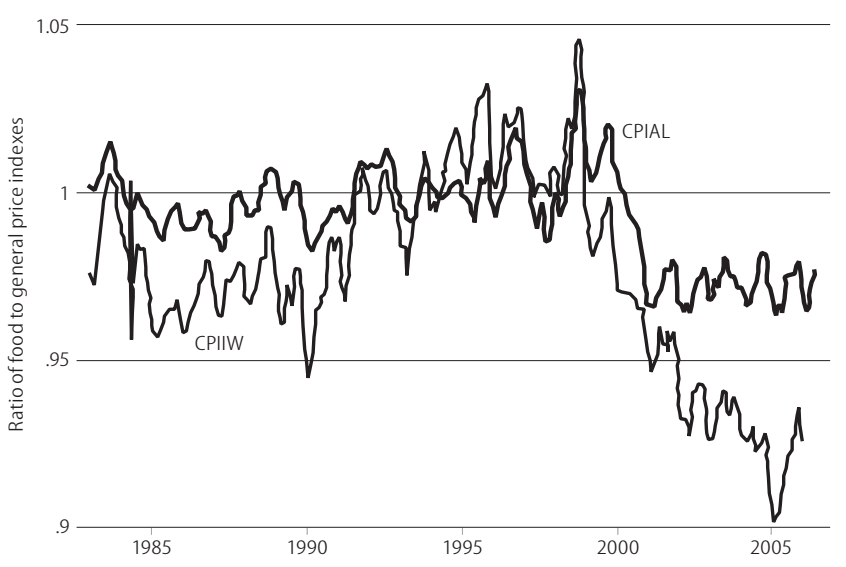

the calorie requirements, by definition. The answer to this is likely to be "no". Indeed, since the poverty line has constant purchasing power in real terms, and since the relative price of food (and thus of calories) did not change much from 1983 until 2004-05, purchasing that baseline food basket with its recommended calorie content would require these poverty line households to spend the same share of total per capita expenditure on food as in the initial scenario. In fact, the food share has fallen at all levels of per capita expenditure, including the poverty line. Thus, it is not possible for households around the poverty line to purchase their initial food basket within their current food budget.

In short, there is no simple "revealed preference argument" that refutes the hypothesis of a squeeze in the food budget due to rising essential expenditure on non-food items. It is worth noting, however, that in the event of such a squeeze, one would expect poor households to switch towards cheaper calories. But the opposite is actually happening - poor rural households have made a modest switch towards more expensive calories, away from cereals and other sources of cheap energy, see Figure 3. This does cast some doubt on the hypothesis of a squeeze in the food budget. It is also consistent with the possibil-

$\begin{aligned} & \text { Table 14: Chained Laspeyres Price Indexes, Round } \\
& \text { by Round, Food Prices and Coarse Cereal Prices }\end{aligned}$
\begin{tabular}{lcccccc}
\hline & \multicolumn{2}{c}{ Rural } & & \multicolumn{2}{c}{ Urban } \\
\cline { 2 - 3 } \cline { 6 - 6 } & Food & Coarse Cereals & & Food & Coarse Cereals \\
\hline $38-43$ & 1.353 & 1.139 & & 1.399 & 1.150 \\
\hline $43-50$ & 1.780 & 1.598 & & 1.796 & 1.762 \\
\hline $50-55$ & 1.804 & 2.075 & & 1.785 & 2.253 \\
\hline $55-61$ & 1.118 & 0.940 & & 1.168 & 1.000 \\
\hline $38-61$ & 4.857 & 3.55 & 5.238 & 4.565
\end{tabular}

Source: Authors' calculations from the unit values in the NSS surveys. ity that people need fewer calories today than they used to, an alternative hypothesis we examine below.

(v) Are the Calorie Engel Curves Misleading?: Another possibility is that the Engel curves in Figures 1 and 2 are biased, and that the true Engel curves are actually downward sloping, which could possibly reconcile the cross-section and time-series evidence without any need to account for downward shifts in the curve. This is only a real possibility for the cereal calorie curves; for total calories, the estimated Engel curves are steep - so that there is a high slope to explain away - and it is not plausible that richer people consume fewer total calories than poorer people do. Some support for the idea that cereal calories fall as people get better-off comes from NNMB data, which show per capita consumption of cereals declining with household income (e g, NNMB 1999, Table 6.9). Somewhat similar results are reported by Subramanian (2003) using an NCAER survey of 2,000 rural households. He estimates cereal Engel curves that slope up among the poorest households, but are flat throughout most of the range of per capita income, similar in shape to some of the recent urban curves in Figure 2. Income is notoriously difficult to measure in rural India, especially for self-employed cultivators, and measurement error can easily cause the Engel curve to be spuriously flattened. However, measurement error will only turn a negative slope into a positive one if richer people systematically report lower incomes than poorer people, which is quite unlikely.

One possible source of bias in the NSs Engel curves arises from the fact that, in the Nss surveys, both total expenditures and total calories are estimated by "adding up" expenditures and quantities applying to various goods (in the NNMB surveys, by contrast, there are independent questions on income and food intake). Thus, measurement errors in reported quantities of goods will find their way both into total expenditures and totals (or subtotals) of calories, and this common measurement error biases the estimated slope of the calorie Engel curve towards unity, and could conceivably convert a true negative slope into an apparent positive one, see Bouis and Haddad (1985) and Subramanian and Deaton (1996). It is difficult to deal with this problem in a convincing way. The standard treatment is to look for some variable that is correlated with total expenditure, but which is measured in a way that is not contaminated by the measurement errors that are common to calories and to expenditures. We have done some experiments along these lines, for example using the ownership levels of the various durable goods that are collected in the Nss surveys. Better-off people are more likely to own a bicycle or an electric fan, so we can follow Filmer and Prtichett (2001) and compute an index of durable ownership that can be thought of as a proxy for living standards.

These experiments yield suggestive but ultimately inconclusive results. The simple count of the number of durable goods owned is (a) strongly positively correlated with per capita total household expenditure, and (b) negatively correlated with per capita consumption of cereal calories, which is consistent with the view that per capita cereal calories are negatively correlated with income, and that the Engel curves in Figure 2 are biased by the common measurement errors. One problem with this story is that it is possible that ownership of at least some of the durable goods is directly linked to the consumption of cereals, not just indirectly as a proxy for living standards. Consider, for instance, the fact that household ownership of a bicycle or motorcycle is a positive predictor of per capita expenditure and negative predictors of cereal consumption. This could simply reflect that people who own bicycles do not use as many calories in walking to work or to school, rather than the fact that ownership of a bicycle indicates higher income and, through higher income, lower cereal consumption. Indeed, the increased ownership of (human) energysaving durable goods over the last decade or two is likely implicated in the calorie decline, at least to some extent. Another 


\section{Figure 10: Access to Piped Water, 1981 and 2001}

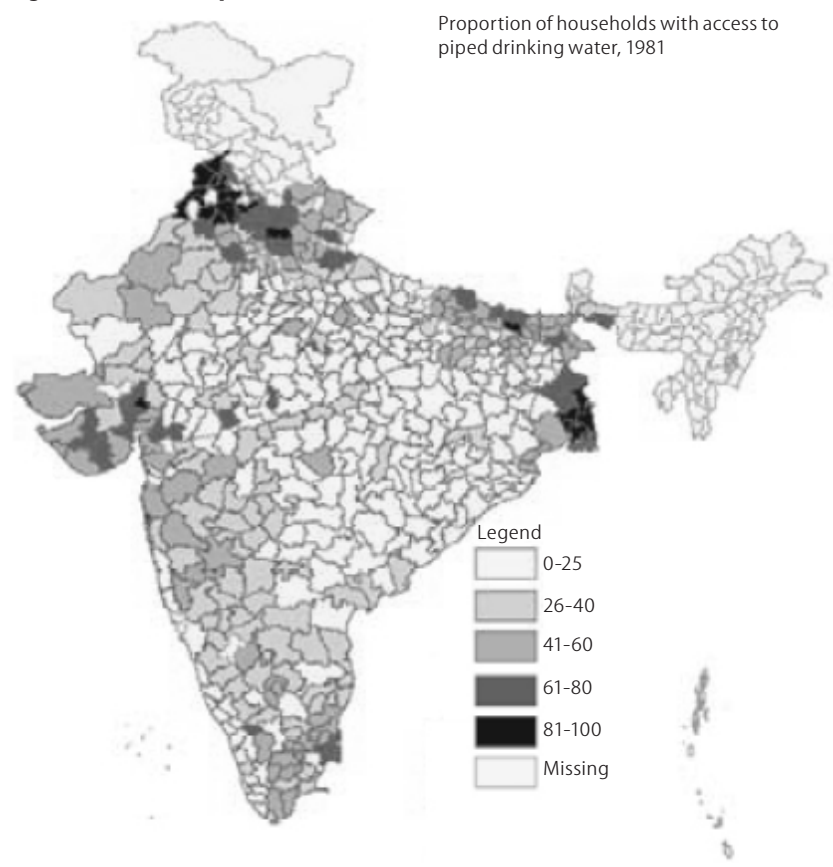

problem is that these results are not replicated if we run the regressions state by state, or even if we pool states but allow for state dummies. Yet if the common measurement error account is correct, it should hold within states as well as across them.

(vi) Changes in Food Habits and Non-Market Entitlements: A simple explanation for the shift from cereals, albeit a not very informative one, is that there has been a change in "consumer tastes", and some econometric studies have taken this route, at least implicitly, by including unexplained time trends in the analysis. While invoking changes in tastes is not helpful in itself, the last few decades have seen important changes in food habits in rural India that are not easily explained by standard factors such as changes in income and prices. Consider for example the sharp decline in the consumption of "coarse cereals". Insofar as coarse cereals are "inferior goods" (with a negative income elasticity of demand), this decline can be interpreted as an income effect. But there is obviously more to it, since the consumption of coarse cereals is also falling at any given level of per capita expenditure.

There are various possible reasons for this decline: growing emulation of the consumption patterns of affluent groups, exposure to new food items, influence of advertisement, and changes in food habits (specifically, substitution towards wheat and rice) induced by the Public Distribution System. It is possible that some of these changes have nutritional consequences about which people are not fully informed, for example, for the consumption of important micronutrients. To illustrate, while "coarse cereals" are generally considered quite healthy and nutritious by nutritionists (some of them even argue for calling them "nutritious grain" rather than "coarse cereals"), they may or may not be perceived as such by the consumers. Conversely, the nutrition value - or lack of it - of "junk foods" (some of which are rapidly gaining popularity in India, and not just in urban areas) is not

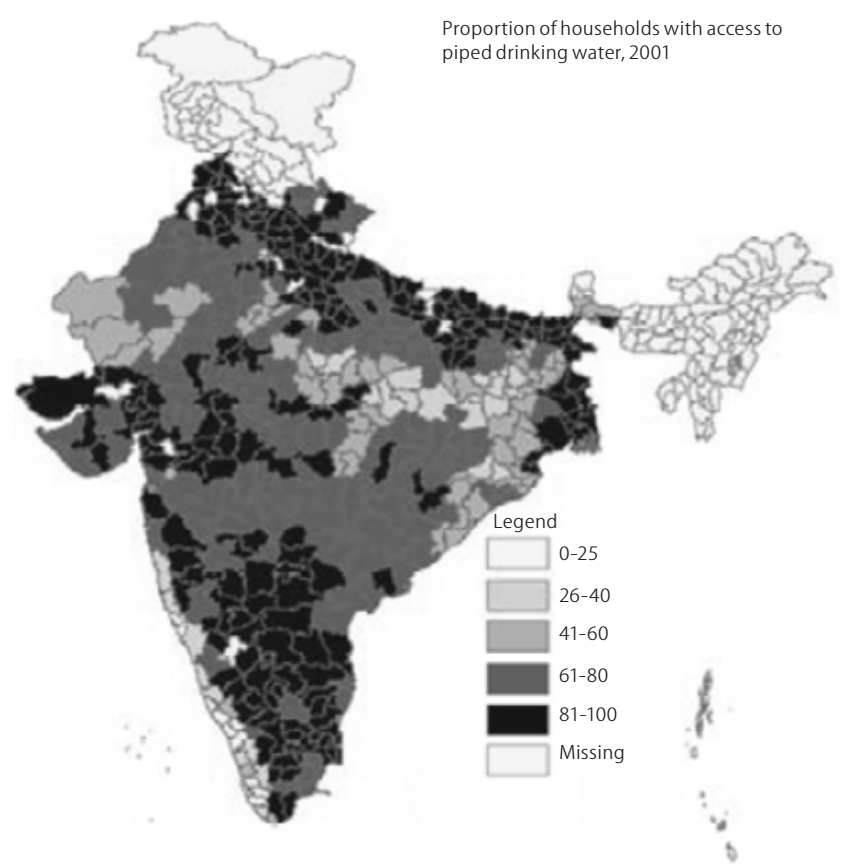

always adequately understood. Thus, it is conceivable that recent changes in food habits (in particular, the decline in coarse cereal consumption) have had nutritional consequences that are not fully appreciated or taken into account by consumers.

A related issue concerns the decline of certain types of food entitlements, not necessarily well captured in Nss-type data. For instance, buttermilk used to be widely available, often free of cost, in many Indian villages, particularly in the north-western region. In those days, large quantities of buttermilk were available as a by-product of ghee, butter and other local milk products. In many villages there was no market for buttermilk it was just consumed at home or given away to neighbours, friends and visitors. With the growing commercialisation of milk, these local processing activities have declined, and so has the availability of buttermilk. It is unlikely that this steep decline in the consumption of buttermilk is adequately captured in standard NSs data. Similarly, as the role of home-grown consumption has lessened, the effective price of food is likely to have risen in a way that is not captured in the usual indexes and which may help explain some of the decline in cereal consumption among the poor; the size of this effect is hard to document with available data.

Some studies (e g, Das Gupta 1985, Jodha 1986) have also noted the decline of a range of traditional food entitlements in various parts of rural India, such as the growing scarcity of wild spinach (saag) due to recent changes in cropping patterns, the reduced availability of fish in rice fields due to pesticide use, and deprivation of forest products or common property resources due to environmental degradation. All this could have an adverse impact on food intake and nutritional status. However, it does not help to explain the decline in measured calorie consumption (if these items were not covered by household survey data in the first place), or for that matter in cereal consumption, especially among the better-off sections of the population. 
(vii) Declining Needs for Calories? The declining consumption of calories has to be examined relative to changes in the various factors that might affect the need for calories. For example, as mentioned earlier the decline of the total fertility rate - from 6.6 in 1960 to 5.0 in 1980 and 2.8 in 2005 - is a source of reduction in requirements (since pregnant and lactating women need more calories), though if those requirements are not met, this may not have had much effect on actual calories consumed. For the same reason, but working in the opposite direction, households today have fewer children relative to adults, so that the decline in per capita calories has most likely understated the decline in calories per adult equivalent.

\begin{tabular}{|c|c|c|c|c|}
\hline \multirow{2}{*}{$\begin{array}{l}\text { Proportion of Adult Men Engaged } \\
\text { in "Moderate Activity" }\end{array}$} & \multicolumn{4}{|c|}{ Proportion of Adult Men Engaged in "Heavy Activity" } \\
\hline & $10 \%$ & $20 \%$ & $40 \%$ & $60 \%$ \\
\hline $10 \%$ & 2,608 & 2,745 & 3,020 & 3,295 \\
\hline $20 \%$ & 2,653 & 2,790 & 3,065 & 3,340 \\
\hline $40 \%$ & 2,743 & 2,880 & 3,155 & 3,430 \\
\hline $60 \%$ & 2,833 & 2,970 & 3,245 & na \\
\hline
\end{tabular}

Source: Calculated from Indian Council of Medical Research (1990), page 29. Each cell indicates average calorie requirements when the proportion of adult men engaged in "heavy activity" is as indicated in the column title, the proportion engaged in "moderate activity" is as indicated in the row title, and other adult men are engaged in "sedentary activity". The estimated calorie requirements for each group are: heavy activity 3,800 calories; moderate activity 2,875 calories; sedentary activity 2,425 calories. All this applies to the "average Indian man", weighing $60 \mathrm{kgs}$.

One possible source of falling calorie requirements is an improved epidemiological environment, with less exposure to disease and infections. For example, there has been a major improvement in access to safe drinking water during the last 25 years or so: the proportion of households with access to piped water has risen sharply across the country, see Figure 10. While piped water is not necessarily safe, much of the increase came from the construction of handpumps and tubewells, whose water is usually safe, and certainly safer than water obtained from rivers, tanks, or open wells. Better water reduces the prevalence of diseases, especially diarrhoeal disease, and removes a potentially major source of calorie wastage. ${ }^{10}$ Other improvements in the disease environment may also reduce calorific needs. For instance, child vaccination rates have risen, and child health improves with mother's education, which has also risen rapidly in recent years. To the extent that these and other improvements in the health environment reduce the susceptibility of children (and adults) to disease and infection, calorie requirements would be reduced.

Another possible source of reduction in calorie requirements is the reduction of activity levels (especially in rural areas), see for example Rao (2000, 2005). Aside from reducing exposure to disease, improved access to piped water is likely to reduce the energy requirements associated with fetching and carrying water, a strenuous task (typically assigned to women and children in rural India). Similarly, the extension of road coverage and transport facilities has enabled more people to use motorised transport, and to save some of the energy spent earlier on long walks (another strenuous activity, especially when it involves carrying heavy loads). The general mechanisation of domestic activities and agricultural work would also contribute to reduced calorie requirements. For instance, aside from fetching water, rural women used to spend much energy on grinding flour at home (using heavy stone mills known as chakkis), but today this is typically done outside the home with energised devices such as electric mills.

The Nss survey data show a large increase in the ownership of durable goods over the last two decades, and many of these goods are likely to reduce the expenditure of human energy. In rural and urban India in 2004-05, 56 and 50\% of households reported owning a bicycle, compared with 17 and $19 \%$ in 1987-88. In 2004-05, 31\% of urban households owned a motorcycle, and 6\% owned a car. Although the rural figures are only a third as high, there has been an almost tenfold increase in ownership rates over 17 years. The most recent figures are broadly confirmed by NFHS-3, which estimated that in 2005-06, $12 \%$ of rural households and $32 \%$ of urban households owned a means of motorised transportation. Television watching, a sedentary leisure activity, has also increased: $30 \%$ of rural and $74 \%$ of urban households now own a television, and these estimates are the same in both surveys. In $1987-88$, less than $1 \%$ of Indian households possessed a television.

The importance of accounting for activity levels in any caloriebased assessment of nutritional status arises from the fact that calorie requirements increase quite sharply with the level of activity. According to the Indian Council of Medical Research (ICMR), the calorie requirements of an "average Indian man" (weighing 6o kgs) are almost 60\% higher if he is engaged in "heavy activity" rather than "sedentary activity" - 3,80o calories and 2,425 calories, respectively. Clearly, looking at calorie intake independently of activity could be quite misleading when the former varies so much with the latter.

For further illustration, Table 15 shows how the average calorie requirements of adult men vary with activity patterns, according to ICMR data. In this table, the column title indicates the proportion of the population engaged in "heavy" activity, the row title indicates the proportion engaged in the "moderate" activity, and it is understood that the rest of the population is engaged in "sedentary" activity. The cell entries give the corresponding average requirements, e g, 2,790 calories per day when the proportions of adult men engaged in moderate and heavy activity are $20 \%$ each. As the table indicates, relatively moderate reductions in activity levels would lead to reductions of calorie requirements of the same order as those that have been actually observed during the last 25 years or so (see Table 1). For instance, a reduction in the proportion of adult men engaged in "heavy activity" from 40 to $20 \%$, with no change in the proportion engaged in "moderate activity", would lead to a decline in average calorie requirements of close to $10 \%$, similar to the actual decline in average calorie consumption in rural areas between 1983 and 2004. It is also reasonable to expect that the percentage activity reductions would be larger among the better-off households, especially if a substantial part of the calorie reduction reflects a substitution of mechanical for human power. This would help to explain why the reduction in calorie intake is itself larger at higher levels of per capita expenditure.

This line of explanation also helps to interpret the rural-urban contrasts. As Figures 1 and 2 show, there have been marked reductions of cereal and calorie intake (at any given level of per 
capita total expenditure) in both sectors, but the decline has been larger in rural areas, and the rural-urban gap has narrowed over time, especially in the lower part of the per capita expenditure distribution. The rural-urban contrast, with lower intake levels in urban areas, has been traditionally attributed to differences in activity patterns, including the more sedentary lifestyle of a large fraction of the urban population, the heavy energy demands of agricultural and domestic work in rural areas, and the lack of transportation in the rural sector. The fact that calorie intake is going down in both sectors, but with larger reductions in rural areas, fits the activity story. The continuity across the two sectors in Figures 1 and 2, albeit with a lag of more than 20 years, is consistent with the notion that the rural sector is becoming more like the urban sector in its activity patterns over time. ${ }^{11}$

This interpretation of the calorie decline, in terms of reduced requirements associated with lower activity levels, is difficult to substantiate further in the absence of reliable data on activity patterns. Detailed time-use studies would also be useful in this context. Fragments of activity and time-use data are actually available in Nss data sets and elsewhere, and could possibly be used to shed further light on this issue. Meanwhile, the activity story does have some plausibility, and this also applies to the more general notion that calorie requirements have declined, due not only to reduced activity levels but also to better health.

(viii) Engel Curves Re-examined: The focus on activity can also help to understand some features of the Nss-based Engel curves for calories and cereal calories in Figures 1 and 2. The basic point to recognise is that food consumption has a "dual" role. On the one hand, food is like any other commodity, which is valued (a source of "utility") for various reasons such as the pleasure of eating, the pursuit of better health, and the role of food in social occasions. On the other hand, calories are required to meet one's immediate energy requirements, themselves contingent on activity patterns. In particular, energy expenditure is required to work and earn. ${ }^{2}$

From this perspective, the distinguishing feature of cereals is that they provide a cheap (often the cheapest) source of calories. At low levels of income, energy requirements tend to be met mainly from cereals, because other foods are unaffordable. As income rises, people typically switch to other, more expensive sources of calories that are also valued from the point of view of taste, healthiness, status, and so on. The calorie requirements, for their part, depend partly on the amount of work people do.

To see the implications of cereals being valued mainly as a source of cheap calories, and in particular as a cheap "fuel" for work, suppose that this is their only purpose. Further, consider a population of rural workers who vary in terms of the amount of work they do, for reasons that might include differences in health, in physical fitness, in work opportunities, or in individual preferences. For instance, some may be able to find work, others not; some may be able to put in long hours of hard work while others have limited strength or suffer from illness; and some may simply choose to work hard and earn more while others prefer a more leisurely life. To keep things simple, assume (to start with) that these workers face the same wage rate, and that calorie requirements depend exclusively on work.

In this setting, which we think of as applying to agricultural workers, we would find a positive relationship (across households) between total expenditure and calorie intake, because both are driven by a third factor, which is the amount of work people do and the effort they put into it. At these low levels of income, this relationship would be much the same for calories and cereal calories, since calorie requirements are met mainly from cereals. At somewhat higher income levels, the Engel curve for cereal calories would flatten out (and possibly even have a negative slope) as other sources of calories substitute for cereals.

What happens over time is different. As the wage rises, and with less work being required to earn a given amount of income, there will be a downward shift in the calorie Engel curve. This may be accentuated by technological change of the sort we have discussed in the preceding section. In the process, calorie intake

\section{Figure 11: State Averages of Cereal Calories and PCE, Large Rounds}

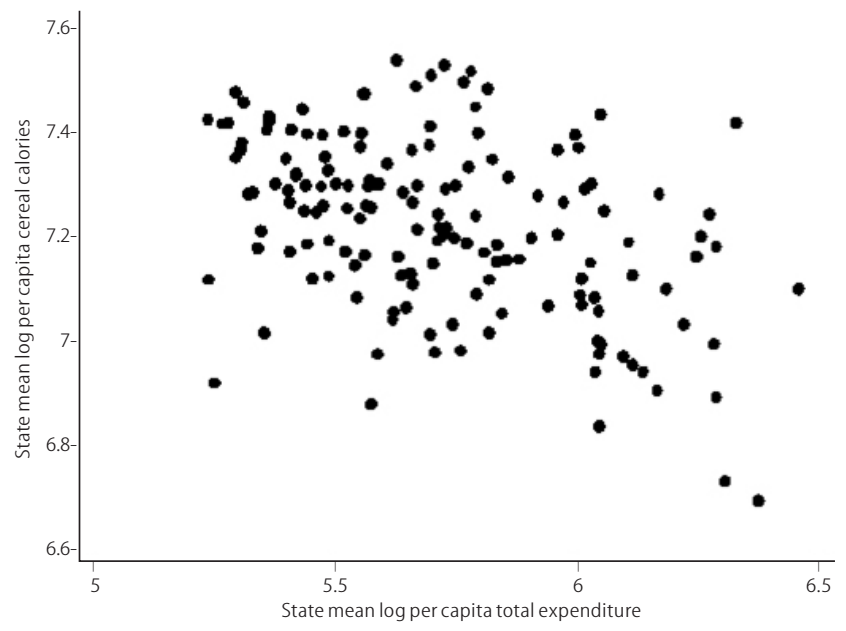

may decline as incomes rise, in contrast to calorie intake increasing with income in the cross-section at a given point of time. To look at it another way, and emphasising once again that we are talking about the lower portion of the Engel curve, variations in income over time are driven (in this model) by wage variations, while those observed at a given point of time are driven by variations in work and effort. The corresponding segments of the Engel curves may have opposite slopes, positive in the crosssection but negative over time.

This is a simplified model that applies, at best, to people with low wages whose income depends mainly on physical labour. To bring it closer to reality, we also have to bring in the people at the top of the Engel curve, among whom variations in income at a moment in time are more likely to be due to variations in wages (or salaries) than to variations in work and effort. Among these better-off workers, it is reasonable to expect a negative relationship between cereal intake and income, partly because people are less likely to be involved in strenuous activities as they become better off, and partly because they would substitute away from cereals towards other foods. Calorie intake may rise or decline with income: even if activity levels are lower at higher 


\section{Figure 12: Underweight Children and Per Capita Calorie Consumption}

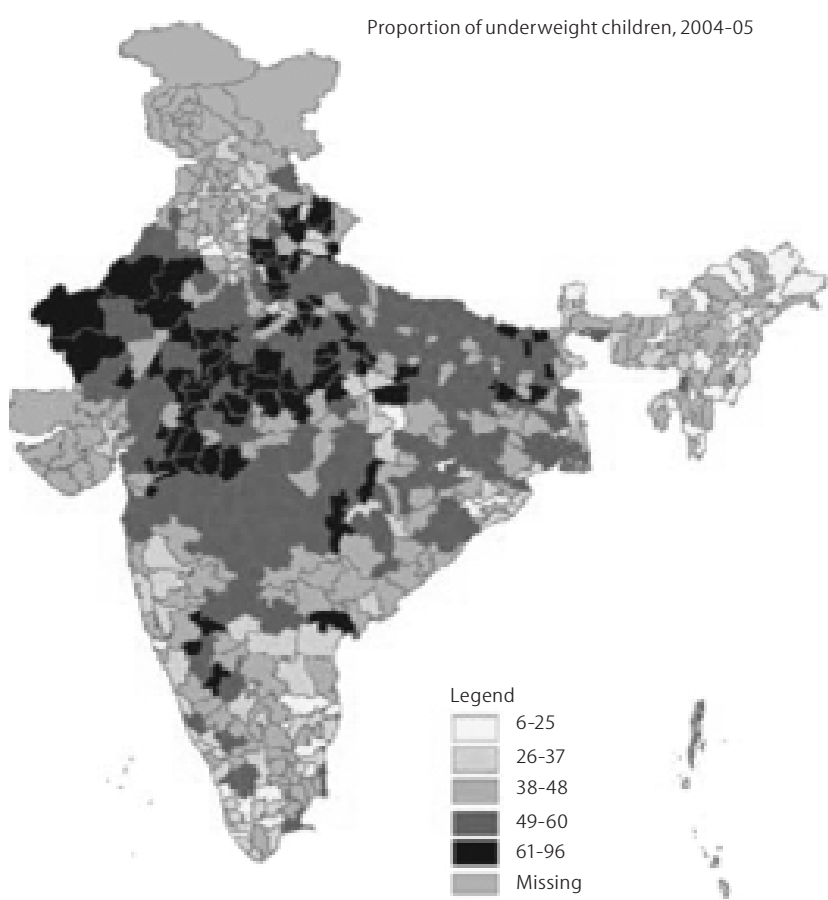

levels of income, there are likely to be positive income effects that cause people to consume more. When wages rise over time, the earlier reasoning would still apply to the extent that the Engel curve is driven by variations in effort and work opportunities across people at any given wage. In addition, at higher levels of income, there may be substantial scope for reducing activity levels over time by adopting labour-saving technology such as agricultural machinery, courtyard hand-pumps, domestic appliances, and so on, some of which are expensive and more affordable by the better-off.

This reasoning is also relevant in interpreting contrasts in calorie consumption between different places, e g, Indian states. Within states, the Engel curves would have the shapes discussed earlier, with a relatively steep positive slope at the bottom, and some flattening (and possibly even a negative slope, in the case of cereal calories) at the top. But across states, things would look different, because the interpersonal differences in ability and opportunity to work would largely average out. Thus, across states, there would be a negative correlation between per capita expenditure and cereal calories, driven by differences in wage rates. The correlation between per capita expenditure and total calories, for its part, may be positive or negative, depending on the strength of different income effects. In fact, the correlation between state averages of per capita cereal calories and per capita expenditure (in logs) is - 0.44 (see Figure 11, p 58) while for per capita total calories, the correlation is 0.53 . This pattern for cereal calories, which appears to conflict with the upward-sloping Engel curves emerging from household data in Figure 2, is quite plausible in this activity-focused approach. It is, of course, also possible that this negative correlation is coincidental, in the sense that it reflects regional variations in calorie requirements (related, for instance, to the climatological or epidemiological environment) or food habits that have little to do with the factors discussed in

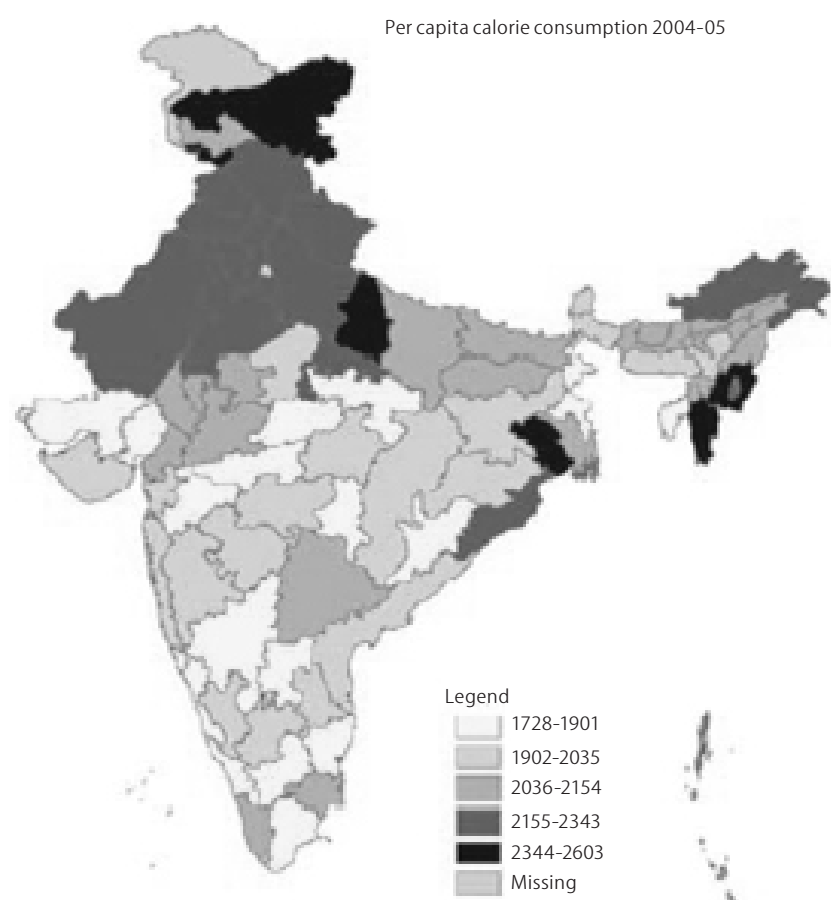

this section. Nevertheless, it is interesting that, here again, the observed features of Nss-based Engel curves are consistent with the recognition of activity levels as an important determinant of calorie requirements.

This completes our brief tour of alternative explanations for the recent decline of calorie intake in India. If only by default, the hypothesis of declining calorie requirements commands serious attention as a possible clue to this puzzle. However, it would be premature to endorse it in the absence of adequate evidence on activity levels and other determinants of calorie requirements.

Because of the uncertainty as to what is going on, it is also difficult to assess the welfare implications of the decline in calorie intake. Had real wages and real incomes increased faster at the bottom of the distribution, it is likely that calorie consumption would have increased, at least for some sections of the population, and possibly even on average. On the other hand, to the extent that the calorie decline is driven by lower activity levels or a better health environment, it may be associated with improvements in some aspects of well-being (such as freedom from hard labour) that escape assessment in the standard poverty estimates and well-being indicators. ${ }^{13}$

\subsection{Nutritional Status}

(i) Farewell to Calorie-based Nutrition Assessment? One important lesson from the preceding discussion is that average calorie intake per se is a poor indicator of the nutritional status of the population (on this see also Vaidyanathan 2003). Calorie requirements seem to be highly context-specific, depending on activity levels, the epidemiological environment, the composition of the population, and other factors. Thus, simple comparisons of nutrition levels (say, between different regions or periods of time) 
based on average calorie intake can be very misleading. Indeed, average calorie intake in India is lower today than it was 20 years ago, yet the nutritional status of the population has improved. Similarly, looking across the districts and regions of India, the correlation between average calorie intake and, say, the nutrition status of children is negative, as Figure 12 (p 59) illustrates: child nutrition is worse in regions with higher levels of per capita calorie intake. ${ }^{14}$ Even if there were a simple relationship between individual nutritional status and calorie consumption, there would be serious perils in making comparisons of nutrition based on Nss-type data on per capita calorie intake for various population groups, or even at the household level, with no idea of its distribution across people, let alone whether the distribution over individuals matches individual calorie needs.

As discussed below, this does not detract from the importance of calorie intake in achieving better nutrition. It does mean, however, that approaches to nutrition assessment based on calorie intake data and "fixed" calorie norms (or on simple comparisons of average calorie intake) are both incomplete and misleading. There is a strong case not only for paying attention to other aspects of food intake (such as the consumption of essential vitamins and minerals) but also for shifting the focus away from food intake towards more "direct" indicators of the nutrition status of the population, such as the growth curves of children or other evidence of nutrition-related impairments.

Energy adequacy depends on net intake, which is calorie intake less the calories absorbed by a range of demands depending inter alia on the epidemiological environment as well as activity levels, and is influenced by variables such as age, birthweight, mother's education, breastfeeding practices, the composition of the diet, to cite a few. Adequate nutrition also requires a host of other inputs that are not adequately summarised by total calories, including a range of micronutrients and, at certain stages of life, especially childhood, a varied diet. Looking at calorie intake, or for that matter other specific nutrition inputs, independently of other relevant variables, is an exercise of limited value for assessing what matters, which is nutritional outcomes. These can be usefully measured by various nutrition indicators such as anthropometric measurements, at least insofar as they capture the combined effects of various inputs (food and non-food) net of other demands.

Having said this, there are also possible difficulties with the use of anthropometric indicators based on currently available data. As noted earlier, for instance, different anthropometric indicators (e g, weight-for-age and weight-for-height) do not always move in the same direction, and sometimes the same indicator moves in different directions according to different sources (e g, NFHS and NNMB). There are also unresolved issues about the interpretation of current anthropometric standards, as discussed below.

(ii) Multiple Deficiencies of Indian Diets: Before we proceed, two clarifications may help. First, nothing we have said justifies a downplaying of calorie deficiencies among poor households. Even if the recent decline of calorie intake is due to falling requirements, and has little to do with impoverishment, the fact remains that poor households have serious energy deficits. Had poverty decline been faster, it is quite likely that calorie intake would have risen among underprivileged households (and perhaps even on average). Reducing calorie deficits among poor households remains very important for the removal of nutritional deprivation in India.

Second, by a similar reasoning, the findings we have presented do not detract from the crucial importance of improved diets in India, including not only reduced calorie deficits but also higher - possibly much higher - intakes of various nutrients for large sections of the population. While economic research on nutrition issues in India has tended to focus mainly on calorie intake, nutritionists have been deeply concerned for a long time about a range of nutritional deficiencies, including those of essential minerals and vitamins, animal protein, and fats. As Tara Gopaldas (2006) notes, for instance, "all members of low-income (and even middle income) families are likely to be deficient in vitamins and minerals" ( $p$ 3671). In fact, the deficiencies are large, in relation to current ICMR recommendations. For instance, in the age group of four to six years, the ratio of average intake to "recommended daily allowance" is only $16 \%$ for Vitamin A, 35\% for iron and $45 \%$ for calcium (NNMB data presented in Gopaldas 2006). While there is some debate as to how these deficiencies are best addressed, including lively controversies about the merits of various forms of "micronutrient supplementation", what is not in doubt is that large sections of the Indian population have diets that are missing much that they need.

Similar concerns apply to the intake of fats (Dorin 1999 2002). In rich countries, and among affluent sections of the population in poor countries (including India), fat has acquired a bad name as a harbinger of diabetes, cardiovascular diseases and other illnesses. Yet, fat intake among large sections of the Indian population is almost certainly too low, possibly much too low. This applies in particular to children in poor households. Fat is important for children not only because fat is a calorie-dense food and helps them to achieve adequate calorie intake despite small stomachs, and generally facilitates the absorption of various nutrients, but also because fat is useful in its own right, e g, for the development of the brain (Uauy et al 2001). Current expert recommendations regarding optimal fat intake as a proportion of calorie intake for young children appear to be in the range of 30 to $45 \%$ (wHO 2005 p 16). In India, however, fat accounts for barely $15 \%$ of average calorie intake, according to Nss data, with much lower figures among poor households. According to the National Nutrition Monitoring Bureau, fat intake among Indian children is only about $30 \%$ of the "recommended daily allowance" (National Nutrition Monitoring Bureau 2006, p 14).

Overcoming these massive deficiencies would require a substantial shift from cereal-based diets to more diversified diets. 
Indeed, it is virtually impossible to meet these diverse requirements from a cereal-dominated diet. Even calorie requirements are difficult to meet from cereals alone, especially for children, due to absorption problems. Sometimes, cereal consumption even has an adverse effect on the consumption of essential nutrients. For instance, cereals, legumes, peas and nuts contain phosphorus compounds known as phytates which inhibit the absorption of iron (certain compounds found in tea have similar effects). This inhibition of iron absorption is one reason why irondeficiency anaemia is so widespread in India (Baynes and Bothwell 1990).

In this connection, there is also evidence from international data, suggesting that the diversification of diets is associated with better child nutrition (Arimond and Ruel 2004; see also Rao 2001 and Rao et al 2001 with reference to India). While the shift from cereal-based diets to more diversified diets is already happening to some extent in India (Kumar et al 2007), Indian diets remain very frugal. ${ }^{15}$ To illustrate, according to NFHS-2 data for 1998-99, only $55 \%$ of adult women in India consume milk or curd at least once a week, only $33 \%$ eat fruits at least once a week, and $28 \%$ get an egg (International Institute for Population Sciences 2000, p 242). Seven years later, the NFHs-3 survey yielded the same figure for "milk or curd" ( $55 \%$ ), and only slightly higher figures for fruits and eggs $-40 \%$ and $32 \%$ respectively (IIPs 2007 a p 299). It is hard to see how mass undernourishment could be eliminated in India without a major improvement in the quantity, quality and diversity of food intake among poorer sections of the population.

(iii) Nutrition Status of Privileged Indian Children: So far we have proceeded on the assumption that international anthropometric standards are "applicable" to India. As the NFHS-3 report puts it:

Evaluation of nutritional status is based on the rationale that in a wellnourished population, there is a statistically predictable distribution of children of a given age with respect to height and weight... The use of a reference population is based on the empirical finding that wellnourished children in all population groups for which data exist follow very similar growth patterns before puberty (IIPS 2007a, p 268).

The puzzlingly high levels of child undernutrition in India (and south Asia) point to the possible need to re-examine this assumption. Consider, for instance, Kerala. According to NFHS-3 data, $23 \%$ of children below the age of three years in Kerala are underweight, $16 \%$ are wasted and $25 \%$ are stunted (IIPS 2007a: 273). However, other indicators of child health and wellbeing suggest that children in Kerala are doing quite well. For instance, the infant mortality rate is only 13 per 1,ooo - about the same as in, say, Kuwait, Costa Rica or Malaysia. Generally, child development indicators (other than anthropometric measurements) are much better in Kerala than in countries with similar proportions of underweight children. For instance, the proportion of underweight children in Kerala is not very different from the average for sub-Saharan Africa, but the infant mortality rate in sub-Saharan Africa (around 100 per 1,ooo) is nearly eight times as high as in Kerala. It is, of course, possible that children in Kerala would be doing even better in some respects if they were not "held up" by low weights and heights.
But it is not clear, from available data, what these impairments actually are.

A related puzzle is that child undernutrition is also quite high (according to the anthropometric approach) among well-off households. Here, two different bodies of evidence need to be considered. On the one hand, some studies (e g, Agarwal, Uphadhyay et al 1987, Agarwal, Agarwal, et al 1991) suggest that the anthropometric achievements of children in affluent Indian families are much the same as those of well-nourished children elsewhere, and indeed these Indian children are included in the international reference population that forms the basis of the most recent wHO "child growth standards" (wHO 2008). On the other hand, the NFHs data tell a different story, whereby a substantial proportion of Indian children are undernourished even among well-off households. To illustrate, Table 16 shows standard child nutrition indicators for different economic classes, defined in terms of the "wealth index" presented in the NFHS-3 report. ${ }^{16}$ As this Table makes clear, child undernourishment declines sharply with increasing values of the index, as one might expect. However, even among the top 20\% of households, substantial proportions of children are undernourished: $20 \%$ of children are underweight, $25 \%$ are stunted, and $13 \%$ are wasted (again, much the same figures as the sub-Saharan African averages).

Also presented in this table are the "mean z-scores" of children in different economic classes. If children from wealthy households had the same "growth curves" as children from the international reference population, their mean z-scores would be zero. In fact, the mean z-scores are negative throughout the wealth scale.

It is perhaps not surprising that wealth alone provides inadequate protection against stunting or wasting. Following on this, Tarozzi (2008) used NFHs-2 data to investigate the nutrition status of privileged Indian children, where privilege is defined not only in terms of wealth but also involves urban residence, piped water, a flush toilet, and both parents having a high school degree. A little over 400 households in the NFHs-2 sample fall in this category (say "privileged households" for short). For this group of privileged households, an interesting pattern emerges: the mean z-score for "height-for-age" is still negative (-o.88), but the mean z-score for "weight-for-height" is very close to zero (o.105), (Tarozzi 2008, Table 4). In other words, privileged Indian children are somewhat stunted, but they are not wasted.

The absence of any wasting among privileged Indian children is consistent with the plausible notion that these children have an adequate food intake. The question remains as to why they are stunted, in spite of the absence of any significant food deprivation, and presumably also of other basic deprivations (e g, lack of sanitation), given the privileged environment in which these children live. Three possible (and not mutually exclusive) hypotheses are as follows.

- "Social determinants" hypothesis: Stunting among privileged children reflects social factors such as a poor epidemiological environment, inadequate social support, and inappropriate social norms relating (say) to breastfeeding or child feeding.

- "Genetic potential" hypothesis: Indian children do not have the same genetic potential as children in the international 
reference population - they are "naturally" shorter, even when they are well-nourished.

- "Gradual catch-up" hypothesis: Indian children have the same genetic potential as children in the reference population, but it takes time for the heights of privileged children to catch up with the genetic potential, given the history of undernutrition.

The social determinants hypothesis is consistent with the claim that the international anthropometric standards are applicable in India. It implies that privileged children in India are often undernourished, though not due to lack of food. For instance, Bhandari et al (2002) found that, in a sample of well off families in south Delhi, only $61 \%$ of infants were breastfed within 12 hours of birth; only $25 \%$ were exclusively breastfed up to the age of four months; almost two-thirds stopped breastfeeding before the age of one year; and only $2 \%$ were fed non-vegetarian foods within a year (even though $58 \%$ of the sample families were non-vegetarian). These observations indicate that, even in privileged families, breastfeeding and complementary feeding practices are often at variance with current recommendations, such as breastfeeding within an hour of birth and exclusive breastfeeding for six months (Gupta 2006; Government of India 2006). It is quite possible that the same children would have benefited from more effective feeding practices in a more conducive social environment, e $\mathrm{g}$, a society where there is better awareness of these matters and where breastfeeding counselling services (or, say, facilities for breastfeeding at the workplace) are available. Having said this, if the social determinants hypothesis is correct, one would expect it to be reflected in wasting as well as in stunting, and not just in stunting. Yet, as we have seen, there is little wasting among privileged Indian children.

The genetic potential hypothesis, although certainly not disproved, is becoming less accepted in the scientific literature, if only because there is a long history of differences in population heights that were presumed to be genetic, and that vanished in the face of improved nutrition.

The "gradual catch-up" hypothesis has some plausibility, if only because (1) nutritional status is highly influenced by birthweight, and (2) birthweight, in turn, is highly correlated with mother's weight and height. This observation, which is at the root of the notion of intergenerational perpetuation of undernutrition, suggests that it would indeed take time for well-fed children to overcome the burden of undernutrition in the past. The catch-up hypothesis is also consistent with historical evidence about the secular increase in heights in Europe (Cole 2003) as well as with a recent analysis of BMI data for ethnic Indians in Fiji and South Africa (Nubé 2008), though this last might also be consistent with the genetic potential hypothesis.

This hypothesis raises the further question whether wellnourished children suffer from any impairments during the catch-up period, due to being relatively short. Ultimately, the "small but healthy" debate suggested that there are indeed impairments (Dasgupta and Ray 1990). A number of developed country studies also suggest that failure to reach one's genetic potential as a child is correlated with a range of negative outcomes throughout the life course. This applies whether this failure is due to low birthweight, or to poor nutrition after birth, and this suggests that stunted children do suffer from significant impairments even if they are well-fed. The possibility remains that the impairments experienced by these short but well-fed children (e g, those belonging to well off families in Kerala) are less serious than those of children who suffer from inadequate nutrition as well as low birthweights (e g, stunted children in Bihar).

The gradual catch-up hypothesis, if correct, would not invalidate the use of international reference standards to assess the nutritional status of Indian children. Indeed, it is appropriate for reference standards to be based on children who are not only well-fed, but also have adequate birthweights and healthy mothers (so that they are free from any burden of past undernutrition). However, this hypothesis might modify our interpretation of the data, depending on the nature of the impairments associated with stunting during the period when population height levels are rising towards the international norm. It would also make it a little easier to understand why anthropometric indicators appear to improve rather slowly at times (without necessarily implying that the consequences of slow improvement are any less serious), even when there is not only substantial poverty reduction but also major improvements in other determinants of child nutrition, such as maternal education and access to safe water. The gradual catch-up hypothesis may also be of some help in explaining why south Asians are so short: this is what one would expect if the region has a particularly long history of mass undernourishment, and if it takes time (perhaps many generations) to overcome this historical burden.

Having said this, the gradual catch-up hypothesis is of no help in explaining the recent "stalling" of weight improvement among Indian children, if such a stalling has actually taken place (as we saw, there is room for doubt on this). Indeed, if children's weights were improving steadily in the 1980 s and 1990s, it is not clear why they should have stopped improving between NFHS-2 and NFHS-3. This is, as things stand, an unresolved puzzle.

\section{Concluding Remarks}

In this paper, we have examined recent evidence on nutrition in India, and discussed possible interpretations of the facts. The main findings are as follows.

One, there is strong evidence (not only from the nss but also from NNMB surveys) of a sustained decline in per capita calorie consumption during the last 25 years or so. According to NSs data, average calorie consumption in rural areas was about $10 \%$ lower in 2004-05 than in 1983. The proportionate decline was larger among better-off sections of the population, and close to zero for the bottom quartile of the per capita expenditure scale. In urban areas, there was little change in average calorie consumption over this period.

Two, the decline of per capita consumption is not limited to calories. It also applies to proteins and many other nutrients, the major exception being fat consumption, which has increased steadily (in both rural and urban areas) during this period.

Three, it would be difficult to attribute the decline in calorie consumption to declining per capita incomes, or to changes in relative prices. Indeed, the evidence points to rising per capita 
incomes (especially - but not exclusively - among the better-off), with little change in the price of food - or calories - relative to other commodities. Thus, the main point is that per capita calorie consumption is lower today at a given level of per capita household expenditure, and this applies across the expenditure scale, at low levels of per capita expenditure as well as high. In other words, the decline in calorie consumption in rural areas is associated with a steady downward drift of calorie Engel curves, the plots of per capita calorie consumption against per capita expenditure.

Four, one possible explanation for this drift is that calorie requirements have declined, due to better health as well as to lower activity levels. There are fragments of evidence to support this hypothesis, such as major expansions in the availability of safe water, vaccination rates, transport facilities, and the ownership of various effort-saving durables. Given that calorie requirements rise sharply with activity levels, fairly moderate reductions in activity levels (reductions that appear to be well within the realm of plausibility) would go a long way to explain the $10 \%$ reduction in average calorie intake since 1983 . However, this hypothesis remains somewhat speculative, in the absence of direct evidence on activity levels and the associated calorie requirements.

Five, we have argued that average calorie intake has serious limitations as a nutrition indicator. While calorie deficiency is an extremely important aspect of nutritional deprivation, there are too many sources of variation in calorie requirements for standard, time-invariant "calorie norms" to be usefully applied to large sections of the population. Further, close attention needs to be paid to other aspects of food deprivation, such as the intake of vitamins and minerals, fat consumption, the diversity of the diet, and breastfeeding practices. This point is relatively well understood among nutritionists, but is yet to be adequately taken on board in economic analyses of nutrition issues in India.

Six, because there is considerable uncertainty about the causes of the calorie decline, it is difficult to assess its welfare implications. It is almost certainly the case that faster income growth among the poor would have moderated or even reversed the calorie decline. But some of the calorie decline may come from a better health environment or a reduction in the burden of hard labour, each of which is a positive development in its own right.

Seven, the limitations of intake-focused nutritional assessments reinforce the case for supplementing intake data with outcome-focused indicators, such as anthropometric measurements. However, anthropometric data have some limitations too. For one thing, there are unresolved puzzles about anthropometric indicators in India, such as the high prevalence of stunting among privileged children (which is seemingly at variance with the premises of accepted "growth standards"). For another, there are inconsistencies between different sources of anthropometric data (specifically, the NFHs and the NNMB), as well as puzzling contrasts between nutrition trends based on different anthropometric indicators, such as height-for-age and weight-for-height. While broad, long-term trends are reasonably clear, there is some confusion about recent changes.
Eight, some of the available anthropometric evidence, particularly from the NFHs, raises troubling questions about the speed of nutritional improvement in India. According to the most recent NFHS data, there has been virtually no change in the proportion of underweight children between 1998-99 and 2005-06 (close to $50 \%$ in both years), and no change in the proportion of adult women with low BMI (also close to 50\%). These undernutrition figures are among the highest in the world, making it all the more troubling that so little progress should have been made during a period of rapid economic growth. Data from the NFHs also suggest that the adult height of Indians - an indicator of nutrition and disease in childhood and adolescence - has improved more slowly than has been the case in other countries, even other countries with similar deficits. Indian women have done particularly poorly. These height data indicate slow progress in nutritional status over a long period - from the late 1950s. Complicating things further, and as discussed in the text, the overall anthropometric evidence on recent nutrition trends for children is far from clear: NNMB data shed a different light on these trends, and even the picture emerging from NFHs data is actually quite mixed, with, for instance, a substantial decline in stunting rates (among children) between NFHS-2 and NFHS-3. Clarification of recent nutrition trends is an important area of further research.

Among other messages emerging from this enquiry is the urgent need for better nutrition monitoring arrangements in India. There are serious gaps in India's nutrition statistics, and even the most basic nutrition trends are far from clear. The NNMB surveys are not particularly informative, given their small sample sizes, limited geographical coverage, confusing methodology, and uncertain quality. The NFHs surveys, for their part, are conducted at wide intervals (six to seven years), and the reports focus mainly on state-level indicators. Effective action in this field requires regular and reliable large-scale surveys that would make it possible to monitor the nutrition situation at the district level at intervals of, say, two to three years at most. Revamping the District Level Health Surveys (DLHS), and conducting NFHS surveys at more regular intervals, are two possible steps in this direction. Another useful option would be to "link" these surveys with Nss surveys from time-to-time, making it possible to combine detailed nutrition data with household expenditure data.

This examination of recent evidence on nutrition in India is far from conclusive. Indeed, it makes clear that the nutrition situation in India is full of "puzzles". We hope that the puzzles, if not resolved, are at least clearer.

\section{NOTES}

1 The NNMB method is as follows: "Dietary intakes are assessed by one day household weighment of raw foods consumed on the day of the survey and assessment of individual dietary consumption by each member during the previous 24 hours. While the family diet survey provides data on the average intakes at the household level, the 24-hour recall method provides information on individual dietary intakes and intra-family distribution of food... The data on dietary consumption is collected using one day weighment method on $80 \%$ of the sample and in the rest, the dietary intakes of the individuals of the household are assessed using 24-hour recall method" (National Nutrition Monitoring Bureau 1997, p 2).

2 This paper does not revisit the "small but healthy" debate that generated lively arguments in the 1980s, as the core issues (e g, the possibility of "costless adaptation" to low food intake) have been largely settled or modified in the light of recent evidence. For useful reviews of this debate, see Dasgupta and Ray (1990) and Osmani (1990). 
3 Until 2006, the World Health Organisation (WHO) recommended the US National Centre for Health Statistics (NCHS) standard, and this was used inter alia in the first and second rounds of the National Family Health Survey. In April 2006 the WHO released new standards "based on children around the world (Brazil, Ghana, India, Norway, Oman, and the United States) who are raised in healthy environments, whose mothers do not smoke, and who are fed with recommended feeding practices" (International Institute for Population Sciences 2007a, p 268). These new standards were used in the third National Family Health Survey (NFHS-3), though nutrition indicators based on the pre-2006 standards are also available from NFHS-3, for purposes of comparison with earlier surveys.

4 The rationale for the selection of these nine particular states (a tenth state, Uttar Pradesh, was added later on) is not clear from the NNMB reports. According to a personal communication from NNMB, they just happen to be the states that responded to initial requests for cooperation from the Indian Council of Medical Research. For a useful appraisal of nutrition monitoring arrangements in India, see Ramachandran (2006)

5 The undernutrition figures are very similar for boys and girls. There is, in other words, little evidence of major gender differences in anthropometric achievements, according to NNMB data. The same conclusion follows from NFHS data. For instance, according to NFHS-3, boys and girls had exactly the same "mean z-scores" in 2005-06, not only in terms of weight-for-age but also in terms of weight-for-height and height-for-age (International Institute for Population Sciences, 2007a, $\mathrm{p}$ 270). This pattern is perhaps a little surprising, considering that there is much evidence of various forms of discrimination against female children in India, reflected inter alia in higher mortality rates for girls than for boys. For further discussion of this issue, see, e g, Harris (200o) and Tarozzi and Mahajan (2007).

6 The NFHS trends mentioned earlier were based on all-India figures, but population-weighted averages of NFHS indicators for the nine NNMB states indicate that the same broad trends (including a marginal decline in underweight between 1998-99 and 2005-06, a larger decline in stunting, and an increase in wasting) apply to the NNMB states as well. The changes are of a similar order of magnitude in both cases.

7 This article is in Chinese; the statement in the text is based on the abstract in English. According to this abstract, the findings are based on a national, representative sample: "Subjects of 71,971 households from 31 provinces were selected by stratified multi-stage cluster random sampling method".

8 This is subject to the earlier qualifications about missing data for specific states in some years. However, as with other anthropometric data for children, it is unlikely that the basic trends would be altered if a consistent series for the same states were to be constructed.

9 International Institute for Population Sciences (2007a), p 304. This is consistent with the NNMB based figures presented in Table 12 for 9 states. The international figures are available at http:// www.measuredhs.com/aboutsurveys.

10 Calorie requirements increase sharply during episodes of diarrhoea. Note, however, that adults or children often reduce calorie intake during episodes of diarrhoea, contrary to expert recommendations (Scrimshaw et al 1983). In that case, reduced exposure to diarrhoea may be irrelevant as an explanation for the calorie decline, though it will enhance the nutritional effects of any given calorie intake.

11 It is also worth noting that, within the rural sector, households that describe themselves as self-employed in agriculture or as agricultural labourers use more calories than do non-agricultural rural households at the same level of per capita expenditure - between $6 \%$ and $14 \%$ less But the shift out of agriculture within the rural sector has been modest (from $74 \%$ of the rural population in 1983 to $64 \%$ in 2004-05), and can only account for a small part of the calorie decline.

12 In terms of standard consumer theory, this suggests that attention needs to be paid not only to the usual "budget constraint", but also to the "energy constraint": Calorie consumption has to be no less than what is required to earn the amount of income associated with the budget constraint.

13 Insofar as the decline in calorie requirements comes from increased ownership of labour-saving durable goods, such as bicycles, motorcycles, or even televisions, the associated expenditures will be captured in the surveys. But the surveys record purchases, not the use-flow associated with durable stocks. In consequence, the Indian boom in durable ownership was recorded in the expen diture figures too early, which biases downward the rates of expenditure growth and poverty reduction.

14 Figure 12 juxtaposes region-level NSS data on calorie intake in 2004-05 with district-level child nutrition data in 2002-04 from the second round of the Reproductive and Child Health (RCH) sur vey, also known as District Level Household Survey (DLHS). On the DLHS-RCH surveys, see Ramachandran (2006).

15 On this, see also Hopper (1999). As the author points out (p 455): "The data indicate that, compared to Indians, Americans consume half the cereals, twice the vegetables, three times the fruit, four times the milk, and 25 times as much meat, while the Chinese consume slightly more cereals, more fruit, two-and-a-half times the vegetables, three times the starchy roots, and almost eight times as much meat as Indians".

16 This index is constructed through "principal components analysis" from a list of 33 household assets and housing characteristics (such as owner ship of various durables, access to electricity, and type of cooking fuel). For further discussion, see IIPS (2007a), pp 43-45

\section{REFERENCES}

Agarwal, D K, S K Upadhyay, A M Tripathi and K N Agarwal (1987): "Nutritional Status, Physical Work Capacity and Mental Function in School Children", Report 6 (New Delhi: Nutrition Foundation of India).

Agarwal, KN, D K Agarwal, D G Benakappa, S M Gupta, P C Khanduja, S P Khatua, K Ramachandran,
P M Udani and C Gopalan (1991): "Growth Performance of Affluent Indian Children (UnderFives): Growth Standard for Indian Children", Report 11 (New Delhi: Nutrition Foundation of India)

Arimond, M and M T Ruel (2004): "Dietary Diversity Is Associated with Child Nutritional Status: Evidence from 11 Demographic and Health Surveys", Journal of Nutrition, pp 134, 2579-85.

Baynes, R D and T H Bothwell (1990): "Iron Deficiency", Annual Review of Nutrition, pp 10, 133-48.

Bhandari, N, R Bahl, S Taneja, M de Onis and M K Bhan (2002): "Growth Performance of Affluent Indian Children Is Similar to That in Developed Countries", Bulletin of the World Health Organisation, 8o(3), pp 189-95.

Bouis, Howard and Laurence J Haddad (1985): "Are Estimates of Calorie-Income Elasticities Too High? A Recalibration of the Plausible Range", Journal of Development Economics, 39, pp 333-64

Bozzoli, Carlos, Angus Deaton and Climent QuintanaDomeque (2009): "Adult Height and Childhood Disease', Demography, forthcoming.

Clark, Gregory, Michael Huberman and Peter Lindert (1995): "A British Food Puzzle, 1770-1850", The Economic History Review, 48(2), pp 215-37.

Cole, Tim J (2003): "The Secular Trend in Human Physical Growth - A Biological View", Economics and Human Biology, 1, pp 161-68.

Das Gupta, Monica (1985): "Informal Security Systems and Population Retention in Rural India", NCAER Working Paper No 2 (New Delhi: National Council of Applied Economic Research).

Dasgupta, Partha and Debraj Ray (1990): "Adapting to Undernourishment: The Biological Evidence and Its Implications" in J P Drèze and A K Sen (ed.), The Political Economy of Hunger, Vol I (Oxford: Clarendon).

Deaton, Angus (2007): "Height, Health and Development", Proceedings of the National Academies of Science, 104(33), pp 13232-37.

- (2008a): "Height, Health, and Inequality: The Distribution of Adult Heights in India", American Economic Review, Papers and Proceedings, 98(2), pp 468-74

(2008b): "Price Trends in India and Their Implications for Measuring Poverty", Economic \& Political Weekly, 9 February, pp 43-49.

Deaton, Angus and Jean Drèze (2002): "Poverty and Inequality in India: A Re-examination", Economic \& Political Weekly, 7 September, pp 3729-48.

Deaton, Angus and Valerie Kozel (2005a): "Data and Dogma: The Great Indian Poverty Debate", World Bank Research Observer, 20(2), pp 177-99. JADAVPUR UNIVERSITY announces
MA in Environment \& Development

- Duration : 2 years (4 semesters)

- Intake : 25; Course fee : Rs.8,000/- per year + Rs.235/- as annual charges.

- Eligibility : Honors/Major graduate in any discipline or Technical/ professional Degree (With preference to person with relevance work experience of at least 2 years).

- Dissemination : Online Web based Distance Learning and Workshops.

- Last Date of application: $6^{\text {th }}$ March 2009.

- Implemented by Directorate of Distance Education, School of Education Technology, JU.

- Fees once deposited cannot be refunded.

For details of Course \& Admission Procedure, please see website : www.jadavpur.edu and www.setju.ac.in/admission 09. 
- (2005b): The Great Indian Poverty Debate (New Delhi: Macmillan).

Dorin, Bruno (1999): "Food Policy and Nutritional Security: The Unequal Access to Lipids in India", Economic \& Political Weekly, 34(26), June, pp 1709-17.

- (2002): Agriculture et Alimentation de l'Inde (Paris: INRA).

Drèze, Jean and Amartya Sen (2002): India: Development and Participation (New Delhi: Oxford University Press)

Du, S, B Lu, F Zhai and B M Popkin (2002): "A New Stage of the Nutrition Transition in China", Public Health Nutrition, 5(1A), pp 169-74.

Flood, Roderick, Kenneth Wachter and Annabel Gregory (1990): Height, Health, and History (Cambridge: Cambridge University Press).

Filmer, Deon and Lant H Prtichett (20o1): "Estimating Wealth Effects without Expenditure Data - or Tears: An Application to Educational Enrolments in States of India", Demography, 38(1), pp 115-32.

Gopalan, C, B V Rama Sastri and S C Balasubramanian (1980): Nutritive Values of Indian Foods (Hyderabad: National Institute of Nutrition), Indian Council of Medical Research (3rd edition).

Gopaldas, Tara (2006): "Hidden Hunger: The Problem and Possible Interventions", Economic \& Political Weekly, 41(34), 26 August, pp 3671-74.

Government of India (2006): National Guidelines on Infant and Young Child Feeding (New Delhi: Ministry of Women and Child Development).

- (2007): Economic Survey 2006-o7 (New Delhi: Ministry of Finance)

Gupta, Arun (2006): "Infant and Young Child Feeding: An Optimal Approach", Economic \& Political Weekly, 41(34), 26 August, pp 3666-71.

Haddad, Lawrence, Harold Alderman, Simon Appleton, Lina Song and Yisehac Yohannes (2003): "Reducing Child Malnutrition: How Far Does Income Growth Take Us?", World Bank Economic Review, 17(1), pp 107-31.

Harris, Bernard (2000): "Height and Nutrition" in K F Kiple and K C Ornelas (ed.), Cambridge World History of Food, Vol 2 (Cambridge: Cambridge University Press), pp 1427-38.

Himanshu (2007): "Recent Trends in Poverty and Inequality: Some Preliminary Results", Economic \& Political Weekly, 1o February, pp 497-508.

Hopper, Gordon R (1999): "Changing Food Production and Quality of Diet in India, 1947-98", Population and Development Review, 25(3), pp 443-77.

Indian Council of Medical Research (1990): Nutrient Requirements and Recommended Dietary Allowances for Indians (New Delhi: ICMR).

International Institute for Population Sciences (2000): National Family Health Survey 1998-99 (NFHS-2): India (Mumbai: IIPS).

- (2007a): National Family Health Survey 2005-06 (NFHS-3): India (Mumbai: IIPS).

- (2007b): 2005-06 National Family Health Survey (NFHS-3): National Fact Sheet (Mumbai: IIPS) (Also available at www.nfhsindia.org).

- (2007c): State-wise Fact Sheets Based on 2005-06 National Family Health Survey (NFHS-3), (Mumbai: IIPS) (Also available at www.nfhsindia.org).

Jodha, N S (1986): "Common Property Resources and Rural Poor in Dry Regions of India", Economic \& Political Weekly, 21(27), 5 July, pp 1169-81.

Kumar, Praduman, Mruthyunjaya and Madan M Dey (2007): "Long-term Changes in Indian Food Basket and Nutrition", Economic \& Political Weekly, 42(35), 1 September, pp 3567-72.

Mahendra Dev, S (2005): "Calorie Norms and Poverty", Economic \& Political Weekly, 19 February.

Mari Bhat, P N (2002): “On the Trail of 'Missing' Indian Females I: Search for Clues", Economic \& Political Weekly, 37(51), 21 December, pp 5105-18.

Meenakshi, JV and Brinda Viswanathan (2005): "Calorie Deprivation in Rural India between 1983 and 1999-2000" in Angus Deaton and Valerie Kozel (ed.), The Great Indian Poverty Debate (New Delhi: Macmillan), pp 570-83.
Meng, X, X Gong and Y Wang (2009): "Impact of Income Growth and Economic Reform on Nutri tion Availability in Urban China: 1986-200o", Economic Development and Cultural Change, 57(2), 261-95.

Minhas, BS (1988): "Validation of Large Scale Sample Survey Data: The Case of NSS Estimates of Household Consumption Expenditure", Sankhya, The Indian Journal of Statistics, 50, Series B, Part 3 , Suppl, 1-63.

National Nutrition Monitoring Bureau (1990): Report of NNMB-NSSO Linked Survey (Hyderabad: National Institute of Nutrition).

(1991): Report of Repeat Surveys (1988-9o) (Hyderabad: National Institute of Nutrition).

- (1996a): Nutritional Status of Rural Population: Report of NNMB Surveys (Hyderabad: National Institute of Nutrition).

- (1996b): Report of NNMB Surveys: Additional Tabulations (Hyderabad: National Institute of Nutrition).

- (1997): 25 Years of National Nutrition Monitoring Bureau (Hyderabad: National Institute of Nutrition).

- (1999): Report of Second Repeat Survey - Rural (1996-97) (Hyderabad: National Nutrition of Nutrition).

- (200o): Report on Food and Nutrient Intake of Individuals (Rural) (Hyderabad: National Institute of Nutrition).

- (2002): Diet and Nutritional Status of Rural Population (Hyderabad: National Institute of Nutrition).

(2005): Assessment of Diet and Nutritional Status of Individuals and Prevalence of Hypertension in Adults and Anemia among Men and NPNL Women in Rural Communities (Hyderabad: National Institute of Nutrition).

- (2006): Diet and Nutritional Status of Population and Prevalence of Hypertension among Adults in Rural Areas (Hyderabad: National Institute of Nutrition).

National Sample Survey Organisation (2001): Nutritional intake in India 1999-200o, Ministry of Statistics and Programme Implementation, Government of India, August.

Nubé, Maarten (2008): "The Asian Enigma: Predisposition for Low Adult BMI among People of South Asian Descent", Public Health Nutrition, published online 29 May.

Osmani, S R (1990): "Nutrition and the Economics of Food: Implications of Some Recent Controversies" in J P Drèze and A K Sen (ed.), The Political Economy of Hunger, Vol I (Oxford: Clarendon).

Palmer-Jones, Richard, and Kunal Sen (2001): "On Indian Poverty Puzzles and Statistics of Poverty," Economic \& Political Weekly, 36(3), 20 January, 211-17.

Patnaik, Utsa (2004): "The Republic of Hunger", Social Scientist, 32(9-10), September-October, 9-35.

- (2007): "Neoliberalism and Rural Poverty in India", Economic \& Political Weekly, 42(30), 28 July, 3132-50.

Piazza, Alan (1986): Food Consumption and Nutritional Status in the People's Republic of China, Boulder, Colo Westview.

Radhakrishna, R (2005): "Food and Nutrition Security of the Poor: Emerging Perspectives and Policy Issues", Economic \& Political Weekly, 40(18), 30 April, 1817-21.

Radhakrishna, R, K Hanumantha Rao, C Ravi, and B Sambi Reddy (2004): "Chronic Poverty and Malnutrition in 1990s", Economic \& Political Weekly, 39(28), 10 July, 3121-30.

Rajan, S I, and K S James (2008): "Third National Family Health Survey in India: Issues, Problems and Prospects", Economic \& Political Weekly, 29 November.

Ramachandran, K (2006): "Nutrition Monitoring and Surveillance", available at http://nutritionfoundationofindia.res.in.
Rao, C H Hanumantha (200o): "Declining Demand for Foodgrains in Rural India: Causes and Implications", Economic \& Political Weekly, 35(4), 22 January, 201-06.

- (2005): Agriculture, Food Security, Poverty and Environment: Essays on Post-Reform India (New Delhi: Oxford University Press).

Rao, Shobha (2001): "Nutritional Status of the Indian Population", Journal of Biosciences, 26(4), Suppl, 481-9.

Rao, Shobha, et al (2001): "Intake of MicronutrientRich Foods in Rural Indian Mothers Is Associated with the Size of Their Babies at Birth: Pune Maternal Nutrition Study", Journal of Nutrition, 131: 1217-24.

Ray, Ranjan and Geoffrey Lancaster (2005): "On Setting the Poverty Line Based on Estimated Nutrient Prices: Condition of Socially Disadvantaged Groups during the Reform Period", Economic \& Political Weekly, 40(1), 1 January, 46-56.

Samson, M, et al (2009): "Struggling to Learn", mimeo, Collaborative Research and Dissemination (New Delhi: forthcoming in Frontline).

Sankar, Deepa (2007): "What Is the Progress in Elementary Education in India during the Last Two Decades? An Analysis Using NSS Education Rounds", mimeo, World Bank.

Sen, Pronab (2005): "Of Calories and Things: Reflections on Nutritional Norms, Poverty Lines and Consumption Behaviour in India", Economic \& Political Weekly, 40(43), 22 October, 4611-8.

Scrimshaw, Nevin S, Oscar Brunser, Gerald Keusch, Ayesha Molla, Imran Ozalp, and Benjamin Torún (1983): "Diarrhea and Nutrient Requirements", Chapter 16 in Lincoln C Chen and Nevin S Scrimshaw (ed.), Diarrhea and Malnutrition: Interac tions, Mechanisms and Interventions (Geneva: United Nations University Press), pp 269-86.

Sharma, Rekha (2006): "Quantifying Malnutrition in India", PhD thesis (Delhi: Delhi School of Economics).

Subramanian, A (2003): "Consumption of Food and Calories: Some Implications for Nutrition and Income" (New Delhi: National Council for Applied Economic Research) processed.

Subramanian, S and A Deaton (1996): "The Demand for Food and Calories", Journal of Political Economy, 104(1), 133-62.

Suryanarayana, M H and D Silva (2007): "Is Targeting the Poor a Penalty on the Food Insecure? Poverty and Food Insecurity in India", Journal of Human Development, 8(1), 89-107.

Tarozzi, Alessandro (2008): "Growth Reference Charts and the Status of Indian Children", Economics and Human Biology, 6(3), 455-68.

Tarozzi, Alessandro and Aprajit Mahajan (2007): "Child Nutrition in India in the Nineties", Eco nomic Development and Cultural Change, 55(3), 441-86.

Uauy, R, D R Hoffman, Peirano, P Birch, and E E Birch (2001): "Essential Fatty Acids in Visual and Brain Development", Lipids, 36(9), 2962S-72S.

Vaidyanathan, A (2003): "Food Consumption and Nutrition Status: A Re-examination Based on Indian Evidence" in A K Bagchi, M Chattopadhyaya and R Khasnabis (ed.), Economy and the Quality of Life: Essays in Memory of Ashok Rudra (Kolkata: Dasgupta \& Co).

Victora, Cesar G, Linda Adair, Caroline Fall, Pedro C Hallal, Reynaldo Martorell, Linda Richter and Harshpal Singh Sachdev, for the Maternal and Child Undernutrition Study Group (2008): "Maternal and Child Undernutrition: Consequences for Adult Health and Human Capital", The Lancet, 371, 340-57.

World Health Organisation (2005): Guiding Principles for Feeding Non-Breast-fed Children 6-24 Months of Age (Geneva: World Health Organisation).

- (2008): "The WHO Child Growth Standards", available at http://www.who.int/childgrowth/en/.

Yang, X G, et al (2005): "Study on Weight and Height of the Chinese People and the Differences Between 1992 and 2002", Chinese Journal of Epidemiology.26(7), 489-93. 